\title{
Review Article \\ The Contribution of Immune and Glial Cell Types in Experimental Autoimmune Encephalomyelitis and Multiple Sclerosis
}

\author{
Samuel S. Duffy, Justin G. Lees, and Gila Moalem-Taylor \\ School of Medical Science, The University of New South Wales, Wallace Wurth Building East, Level 3, Room 327, \\ Sydney, NSW 2052, Australia \\ Correspondence should be addressed to Gila Moalem-Taylor; gila@unsw.edu.au \\ Received 7 August 2014; Revised 27 September 2014; Accepted 27 September 2014; Published 12 October 2014 \\ Academic Editor: Wolfgang Bruck \\ Copyright (C) 2014 Samuel S. Duffy et al. This is an open access article distributed under the Creative Commons Attribution License, \\ which permits unrestricted use, distribution, and reproduction in any medium, provided the original work is properly cited.

\begin{abstract}
Multiple sclerosis (MS) is a chronic inflammatory disease of the central nervous system characterised by widespread areas of focal demyelination. Its aetiology and pathogenesis remain unclear despite substantial insights gained through studies of animal models, most notably experimental autoimmune encephalomyelitis (EAE). MS is widely believed to be immune-mediated and pathologically attributable to myelin-specific autoreactive CD4+ T cells. In recent years, MS research has expanded beyond its focus on CD4+ T cells to recognise the contributions of multiple immune and glial cell types to the development, progression, and amelioration of the disease. This review summarises evidence of T and B lymphocyte, natural killer cell, macrophage/microglial, astrocytic, and oligodendroglial involvement in both EAE and MS and the intercommunication and influence of each cell subset in the inflammatory process. Despite important advances in the understanding of the involvement of these cell types in MS, many questions still remain regarding the various subsets within each cell population and their exact contribution to different stages of
\end{abstract} \\ the disease.
}

\section{Introduction}

Multiple sclerosis (MS) is a chronic demyelinating disease of the central nervous system (CNS), which is at present attributable to a self-sustaining autoimmune mechanism. It is the most prevalent disabling neurological disease affecting young people [1] and one of the most common inflammatory conditions of the CNS [2], affecting approximately 2.5 million people worldwide [3]. Whilst the aetiology of MS is largely unknown, genetic, metabolic, environmental, and immunological factors have all been implicated [4]. The main pathological characteristics of MS are CNS plaques composed of inflammatory cells, demyelinated axons, reduced oligodendrocyte numbers, transected axons, and gliosis. Most lesions develop in the white matter but may also be present in areas of grey matter. MS patients show a wide range of neurological symptoms that originate in different areas of the CNS, which may appear as sudden attacks or as a steady progression. Symptoms include motor deficits (e.g., muscular spasms and weakness), sensory disturbances (e.g., paraesthesia) and neuropathic pain, fatigue, visual disturbances, continence problems (e.g., bladder incontinence and constipation), and neuropsychological symptoms (e.g., memory loss and depression) [5]. Although the clinical course of MS is highly variable, several disease subtypes have been described (Table 1) [6-8]. Progressive MS is a highly disabling condition where increasing paralysis renders $50 \%$ of patients unable to walk within 25 years of clinical onset [9].

Experimental autoimmune encephalomyelitis (EAE) is a widely accepted animal model of MS that has been used to study the pathophysiology of the disease since first being described in 1933 by Rivers and colleagues [10]. It shares many pathological features with MS, such as chronic neuroinflammation, demyelination, and neuronal damage, and is generated by autoimmune attack on the CNS [11, 12]. Immunisation with self-antigenic epitopes of myelin is used to actively induce an autoimmune response in the CNS of rodents and includes myelin oligodendrocyte glycoprotein 
TABLE 1: Subtypes of multiple sclerosis.

\begin{tabular}{lll}
\hline Disease subtype & Characteristics & Disease activity \\
\hline Clinically isolated syndrome (CIS) & $\begin{array}{l}\text { First clinical presentation of a disease that } \\
\text { shows characteristics of inflammatory } \\
\text { demyelination that could be MS but has yet } \\
\text { to fulfil criteria of dissemination in time. }\end{array}$ & $\begin{array}{l}\text { CIS and RRMS may be } \\
\text { (i) not active, } \\
\text { (ii) active (determined by clinical relapses } \\
\text { and/or magnetic resonance imaging MRI } \\
\text { activity). } \\
\text { Active CIS may become RRMS upon } \\
\text { fulfilling MS diagnostic criteria. }\end{array}$ \\
$\begin{array}{lll}\text { Clearly defined disease relapses with full } \\
\text { recovery or with residual deficit upon } \\
\text { recovery. Accounts for approximately } \\
\text { Relapsing remitting MS (RRMS) }\end{array}$ & $\begin{array}{l}\text { Progressive accumulation of disability from } \\
\text { onset. Accounts for 10-15\% of MS patients. }\end{array}$ & $\begin{array}{l}\text { (i) Active and with progression (measured } \\
\text { (ii) Active but without progression }\end{array}$ \\
\hline Primary progressive MS (PPMS) & $\begin{array}{l}\text { Progressive accumulation of disability after } \\
\text { an initial relapsing disease course. Afflicts } \\
\text { up to 90\% of RRMS sufferers after 25 years. }\end{array}$ & $\begin{array}{l}\text { (iii) Not active but with progression } \\
\text { (iv) Not active and without progression } \\
\text { (stable disease). }\end{array}$ \\
\hline
\end{tabular}

(MOG) [13], myelin basic protein (MBP) [14], and proteolipoprotein (PLP) [15], among others. CNS antigens such as these can be highly encephalitogenic and trigger EAE by emulating the characteristic breakdown of the blood brain barrier (BBB) seen in the early stages of MS. This allows multifocal infiltration of activated immune cells into the CNS, which proceed to attack the myelin sheath [16]. An immune response is generally initiated within two weeks of immunisation in the periphery, leading to the typical presentation of ascending paralysis (tail to hind limb to fore limb paralysis) accompanied by a progressive loss in body weight of the animal [17]. EAE represents a range of models with different disease course and pathology, depending on the immunising antigen and the animal species and strain. As such, each EAE model recapitulates a specific repertoire of pathological similarities to those seen in MS. The close clinical and histopathological parallels that can be drawn between specific forms of EAE and MS subtypes suggest EAE to be a useful tool to further our understanding of the mechanisms involved in autoimmunity and may assist in the development of novel therapeutics for MS.

It is worthy to mention, however, that the translational relevance of EAE to MS is highly debated. Despite sharing certain pathogenic features with MS, the unique pattern of demyelination characteristic of MS is not accurately recapitulated in any existing EAE models, and numerous therapies found to be successful in suppressing EAE have often been shown to have limited efficacy in MS. The EAE model also fails in recognising emerging non-autoimmune theories of MS pathogenesis such as virally induced mechanisms and the "inside-out" idea coined by Stys and colleagues [18], whereby MS is proposed to initiate within the CNS as a primary neurodegenerative disorder. The immune response, bringing with it the archetypal inflammatory phenotype seen with MS lesion formation, is suggested to occur secondary to a primary demyelinating event $[18,19]$. Theiler's murine encephalomyelitis virus (TMEV) and neurotropic strains of mouse hepatitis virus (MHV) models are the most widely studied representations of virally induced demyelinating disease, whilst models utilising toxins such as cuprizone or lysophosphatidylcholine may be more useful for investigating mechanisms of demyelination and remyelination [20]. Although important to recognise, alternative theories of the aetiology of MS and insights gathered through models other than EAE are beyond the scope of this review. Our focus is to summarise known immune and glial cell-mediated mechanisms of disease pathogenesis, as brought to light through studies utilising various EAE models and in MS patients.

Currently, MS is most widely thought to be mediated by activation of autoreactive myelin-specific $\mathrm{T}$ cells that enter the CNS and initiate a chronic inflammatory response. This is believed to be accompanied by slow neurodegeneration leading to a progressive decrease in neuronal count and grey matter volume over time [21]. Such neurodegeneration becomes increasingly more predominant as the disease enters its later stages and at present is extremely difficult to treat. The hypothesis of MS as a T cell-mediated autoimmune disease is supported by the fact that adoptive transfer of activated myelin-specific CD4+ T cells can induce EAE [22]. As already stated, this view has recently come under criticism; however, it is nonetheless irrefutable that MS possesses a central inflammatory aspect, which will be explored in this review. Specifically, it has become increasingly clear that pathogenesis of MS and EAE expands far beyond the idea of a solely CD4+ T-cell-mediated autoimmune disease. Rather, it involves various immune cells of both arms of the innate and adaptive immune system, as well as immune-like glial cells. In this review, we summarise the current evidence for the involvement of some immune cell subsets and glial cells in EAE and MS (Figure 1).

\section{Involvement of T Lymphocytes}

The lymphocyte population consists of thymus-derived $\mathrm{T}$ cells, bone marrow-derived B cells, and natural killer (NK) cells. T lymphocytes are a heterogeneous group of cells that function as part of the adaptive immune system and mediate cellular immunity. They can be divided into three broad categories: T helper (Th/CD4+) cells, cytotoxic (CD8+) cells, 


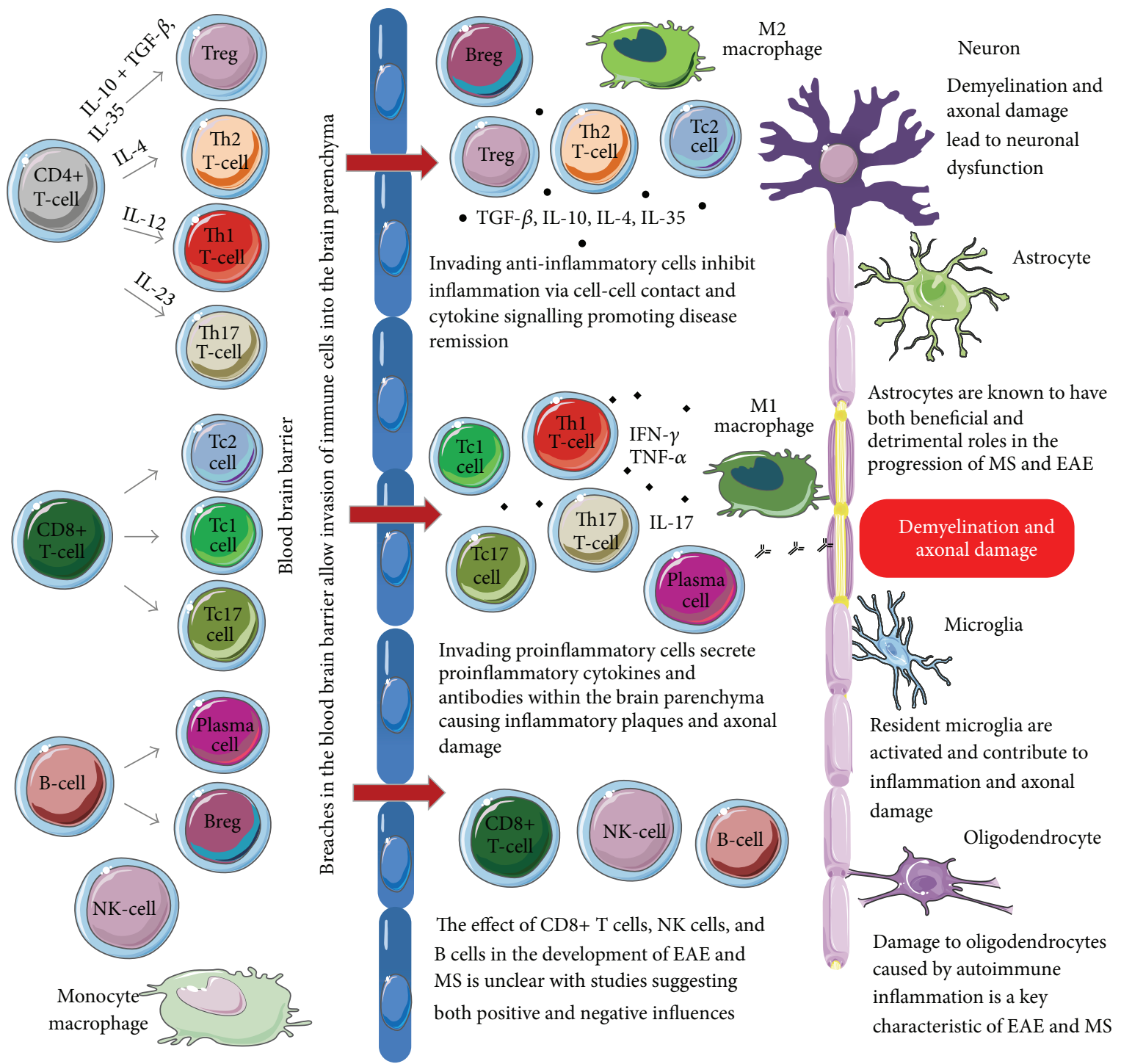

FIGURE 1: Immune and glial cell subtypes and their contributions to the pathogenesis of EAE and MS. During the development and progression of EAE and MS, a variety of cells representing both the innate and adaptive immune system breach the blood brain barrier and invade the brain parenchyma. Resident glial cells also become activated and play an important role in the pathogenesis of EAE and MS. Some of the cell types involved are proinflammatory and promote demyelination, axonal damage, and the formation of disease plaques, whilst other cell types have anti-inflammatory and/or regulatory properties and inhibit disease progression by facilitating tissue repair.

and regulatory $\mathrm{T}$ (Treg) cells. Within each category, $\mathrm{T}$ cells are able to differentiate into distinct subtypes depending on specific cytokine signalling, the expression of chemokine receptors, transcription factors, and epigenetic modifications. Each subset has a different cytokine profile and thus exerts an individualised role in the immune response. $\mathrm{T}$ cells are rare within tissue of the intact nervous system but actively infiltrate the CNS of animals with EAE $[23,24]$ and MS brain and spinal cord lesions $[25,26]$.

2.1. T Helper Cells. CD4+ cells carry out multiple functions including the regulation of innate and adaptive immunity, activation of other immune and non-immune cells, and suppression of immune reactions. MS is commonly conceptualised as being mediated by type $1 \mathrm{~T}$ helper (Th1) cells, which differentiate from naïve $\mathrm{T}$ cells in response to IL12 production by antigen presenting cells [27]. Committed Th1 cells produce predominantly proinflammatory cytokines such as interferon- (IFN-) $\gamma$ and tumour necrosis factor(TNF-) $\alpha$, which have been implicated in EAE and MS.

Administration of a TNF-receptor-IgG fusion protein, a TNF antagonist, has been shown to prevent clinical signs of actively induced EAE; however, total CD4+ cell infiltration appeared unaltered [28]. The timing of TNF-receptor IgG fusion protein therapy was later shown to be critical, as administration prior to the clinical onset of disease markedly 
reduced EAE severity and neurological deficit, whilst established clinical disease was relatively refractory to treatment [29]. Additional studies have shown that TNF-deficient C57BL/6 mice induced with $\mathrm{MOG}_{35-55}$ develop EAE, albeit with delayed clinical onset and a failure of inflammatory leukocytes to migrate into the CNS parenchyma [30]. Treatment of a relapsing-remitting form of EAE with soluble TNF receptor:Fc/p80 given after disease onset ameliorated both clinical deficit during the initial attack and the exacerbation rate for subsequent attacks [31]. The individual roles of the two TNF receptors have also been investigated, with TNF receptor 1 knockout mice shown to develop less severe EAE characterised by minimal demyelination as compared to WT mice. In contrast, TNF receptor 2 knockout mice developed severe EAE with marked demyelination, pointing to both an inflammatory and anti-inflammatory aspect to TNF action that is dependent on alternative activation of its two receptors [32]. In support of such a notion, soluble TNF receptor 1 , a specific inhibitor of TNF- $\alpha$, is able to suppress the development of EAE passively induced by adoptive transfer of MBP-sensitised T cells [33]. Further, TNF receptor 1deficient mice show decreased demyelination and protection from clinical disease, suggesting a role for TNF receptor 1 in oligodendrocyte damage [34].

Despite the consensus of the literature suggesting a pathogenic function for TNF in EAE, there is also evidence of a nonessential or even anti-inflammatory role for the cytokine in disease pathogenesis. TNF knockout mice or mice with disruption to the TNF gene have been shown to develop EAE with high mortality and extensive immune cell infiltration and demyelination in the brain and spinal cord $[35,36]$. TNF gene inactivation has also been demonstrated to convert otherwise MOG-resistant mice to a state of high susceptibility, and TNF treatment in TNF knockout mice dramatically reduces EAE severity [36]. Other studies have shown TNF deficiency to delay EAE onset, yet the cytokine appears unnecessary for disease progression as severe EAE associated with paralysis, widespread inflammation, and primary demyelination eventually develops to a similar extent to that seen in WT animals $[37,38]$. A recent paper testing the effects of TNF- $\alpha$ blockade in $\mathrm{MOG}_{35-55}$-induced EAE mirrors the above results by demonstrating that treatment reduced the incidence and delayed the clinical onset of EAE but had no effect on disease severity once established [39]. Attempts at targeting TNF for the treatment of MS have been similarly disappointing. Soluble TNF receptor IgG fusion protein, despite showing success in treating EAE [28, 29], failed to show benefit in alleviating neurological deficit, disease exacerbations, or lesion formation in RRMS patients [40].

The role of IFN- $\gamma$ and IFN- $\gamma$-producing Thl cells is also unclear. An early study testing the efficacy of IFN- $\gamma$ as a therapeutic option for MS reported significant disease exacerbation after treatment [41]. Transgenic mice expressing IFN$\gamma$ in myelinating oligodendrocytes showed no spontaneous CNS inflammation or demyelination and developed EAE in a manner similar to WT mice following disease induction. However, transgenic mice showed chronic neurological deficit as WT mice were experiencing disease remission
[42]. Th1 cells expressing IFN- $\gamma$ are known to infiltrate in increased numbers into the brain of mice with EAE [43], and blocking IFN- $\gamma$ production has been shown to inhibit the progression of EAE [44]. On the contrary, there are also reports of mice deficient in either IFN- $\gamma$ or its receptor being susceptible to severe EAE $[45,46]$, and injection of neutralising antibodies to IFN- $\gamma$ exacerbates both passively and actively induced EAE $[47,48]$. IFN $-\gamma$ knockout mice also showed delay in the onset of clinical EAE compared to WT mice; however, the peak of the disease was more severe in the knockout animals, suggesting a protective role for the cytokine in late-stage disease [49]. Autoreactive CD4+ cells collected from RRMS patients exhibit a more differentiated Th1 phenotype compared to healthy controls [50], and relapse is associated with increased production of IFN- $\gamma$ [51]. A double-blind placebo-controlled trial evaluating the efficacy of antibodies to IFN- $\gamma$ and TNF- $\alpha$ in active SPMS found that blockade of IFN- $\gamma$, but not TNF- $\alpha$, leads to reduced disability scores, decreased numbers of active lesions, and systemic cytokine changes including increased TGF- $\beta$ production and a decrease in IL-1 $\beta$, TNF- $\alpha$, and IFN- $\gamma$ concentrations [52]. Findings regarding the role of Th1 cell signature cytokines in EAE and MS are largely discrepant, and further research is needed to ascertain their exact role in the pathogenesis of both diseases.

Type $2 \mathrm{~T}$ helper cells (Th2) represent a protective anti-inflammatory subpopulation of $\mathrm{T}$ cells which produce cytokines such as interleukins IL-4, IL-5, IL-10, and IL-13 [53]. Th2 cells polarise in response to an environment containing IL-4 [27] and are believed to exert a suppressive role in EAE. Drugs inducing broad upregulation of Th2 cytokines have been shown to ameliorate EAE and result in a parallel blockade of Th1-like responses, including decreases in IFN$\gamma$, TNF- $\alpha$, and IL-12 $[54,55]$. The use of IL-4 knockout mice has demonstrated inconclusive findings in determining the exact contribution of the cytokine in EAE. While some studies showed a minimal role for IL-4 in disease progression $[56,57]$, others reported increased EAE severity accompanied by extensive inflammatory infiltrates in the CNS as well as increased mRNA levels of IFN- $\gamma$, IL-1, and TNF in IL-4deficient mice compared to WT littermates [58]. IL-4 gene therapy utilising HSV-1 vectors delivered to the CNS has also shown promise in ameliorating EAE. Improved remission to relapse rates and severity of relapses in relapsing-remitting EAE [59], as well as delayed clinical onset, reduced disease severity, decreased inflammatory infiltrates, and reductions in demyelination and axonal loss in a model of chronic EAE [60] have been demonstrated. More recently, overexpression of GATA3, a transcription factor required for Th2 differentiation, resulted in delayed clinical onset and reduced EAE severity [61]. Studies comparing IL-4 and IL-10 knockout mice suggest a stronger anti-inflammatory contribution of IL-10 in the suppression of EAE. IL- 4 deficient mice have been shown to follow a disease course similar to WT littermates, whilst IL-10 deficient mice experience more severe EAE, a lower level of spontaneous recovery, and increases in IFN$\gamma$ and TNF- $\alpha$ production in response to encephalitogenic peptides $[62,63]$. IL-10 gene therapy was also demonstrated to be effective in reversing inflammation-induced paralysis, 
weight loss, glial activation [64], and susceptibility to EAE induction by active immunisation [65]. Peripheral blood mononuclear cells expressing IL-4 have been shown to be significantly elevated in MS exacerbations and progressive MS over controls [66] but also found to be decreased alongside IFN $-\gamma$ in active and stable MS compared to controls [67]. IL-10 has also been demonstrated to be simultaneously upregulated with IFN- $\gamma$ in peripheral blood mononuclear cells collected from RRMS patients [68]. Interestingly, serum IFN- $\gamma$, IL- 4 , and TNF- $\alpha$, but not IL-10, were found to be elevated during the acute stage of MS as compared to controls [69]. During MS relapse, levels of TNF- $\alpha$ and IL-10 were both upregulated in the CSF and serum [70]. These findings are most likely reflective of the inherent heterogeneity of the immune response in MS and suggest that, rather than a sequential Th1/Th2 paradigmatic pattern of expression, Th1 and Th 2 cells are actively involved in the inflammatory milieu at multiple stages of the disease.

In addition to the Th1/Th2 paradigm, the proinflammatory type $17 \mathrm{~T}$ helper cell (Th17) population has also been implicated in the pathogenesis of MS, and Th17 cells infiltrate the inflamed CNS of C57BL/ 6 mice with $\mathrm{MOG}_{35-55^{-}}$ induced EAE [71, 72]. IL-23, produced predominantly by macrophages and dendritic cells, appears critical for Th17 cell differentiation [73]. There is also evidence that IL-23, and not IL-12 (which promotes Th1 polarisation of naïve T cells), may be the critical regulator of autoimmune inflammation of the brain in EAE [74]. Interestingly, IL-23-modulated CD4+ $\mathrm{T}$ cells are able to passively induce EAE and stimulate the production of both IFN- $\gamma$ and IL-17A by myelin-reactive $\mathrm{T}$ cells. EAE development in this particular model was determined to be dependent on IFN- $\gamma$, as IL-17 receptordeficient hosts exhibited a similar clinical course to WT hosts [75]. Despite this, neither of the signature cytokines produced by Th1 or Th17 cells (IFN- $\gamma$ and IL-17, resp.) appears essential for the development of EAE [76, 77]. Nonetheless, Th17 cells sensitised to myelin antigens such as $\mathrm{PLP}_{139-151}$ and $\mathrm{MOG}_{35-55}$ are able to induce EAE following adoptive transfer to naive mice, and in many EAE models, this produces a more clinically severe form of the disease than Th1-mediated EAE $[78,79]$. Th17 cells produce the proinflammatory cytokine IL17 , and mice lacking IL-17 or its receptor have been reported to show an attenuation of CNS inflammation and a marked suppression of EAE severity [80, 81]. Alternatively, Haak et al. showed that mice lacking IL-17A and IL-17F do not show any major alleviation of clinical disease and conclude that IL-17 has at best a marginal contribution to the progression of EAE [82]. Furthermore, repeated subcutaneous injection of a neutralising antibody for the p40 subunit of IL-12 and IL-23 also fails to protect against the development of new lesions in RRMS patients [83]. On the other hand, increased IL-17 expression has been correlated with active or relapsing MS $[84,85]$, and IL-17 receptors on BBB endothelial cells in MS lesions have been implicated as a possible mechanism by which immune cells infiltrate the CNS during MS via disruption of $\mathrm{BBB}$ tight junctions [86]. Although unclear to what extent, Th17 cells and the cytokine IL-17 appear to be significantly implicated in the pathogenesis of both EAE and MS.
Novel subtypes of $\mathrm{T}$ helper cell, such as the IL-9producing Th9 cell and the IL-22-producing Th22 cell, are also likely to be implicated in the pathogenesis of EAE and MS. At present, their precise role and the extent of their influence in both diseases remain unclear.

2.2. Cytotoxic T Cells. Cytotoxic (CD8+) T cells may also contribute to the immune response in EAE, through both the elimination of self-reactive cells or self-antigen sources and the secretion of specific cytokines. Like CD4+ cells, CD8+ cells can be divided into effector subtypes defined by the cytokines they produce, which may be pro- or antiinflammatory. Tcl cells, which produce predominantly IFN$\gamma$, and Tc17 cells, which produce IL-17, are thought to be proinflammatory in nature and are therefore likely to contribute to the pathogenesis of EAE. Tc2 cells on the other hand appear to have a protective role in autoimmunity due to their ability to produce anti-inflammatory cytokines including IL4, IL-5, and IL-10 [87].

$\mathrm{CD} 8+$ cells are known to be able to migrate to the CNS of mice with EAE; however, their role thereafter is highly debated. Early studies in mice immunised with MBP allude to a protective role of CD8+ T cells in EAE by showing that depletion of CD8+ T cells worsens clinical disease [88, 89]. More recently, passive induction of EAE via adoptive transfer of CD8+ T cells sensitised to MOG has been demonstrated to produce a histologically more severe and progressive form of the disease than active immunisation using MOG antigens [90-92]. CD8+ cells have also been shown to be necessary in disease induction, as $\mathrm{CD} 8+\mathrm{T}$ cell deficiency in both Lewis rats immunised with MBP [93] and C57BL/6 mice immunised with $\mathrm{MOG}_{35-55}$ [94] confers resistance to the development of EAE. Conversely, Bettini et al. (2009) argue that $\mathrm{CD} 8+\mathrm{T}$ cells have a limited contribution to EAE induction by showing that $\mathrm{MOG}_{35-55}$-immunised C57BL/6 mice deficient in CD8+ cells do develop EAE; however, disease severity is significantly decreased when compared to mice retaining $\mathrm{CD} 8+\mathrm{T}$ cell function [95]. Adding to the confusion, a recent study showed that CD8+ T cells accumulate in the CNS of mice with EAE, but their presence had no effect on the severity of clinical disease, suggesting that it might be an epiphenomenon rather than a disease-relevant feature [96]. As such, the role of CD8+ T cells in EAE is unclear; however, an approach investigating the involvement of specific effector subtypes and their individual roles in CNS autoimmunity would be a valuable addition to the current knowledge.

CD8+ $\mathrm{T}$ cells are also prominent cell types in the inflammatory infiltrate in human MS patients and may even outnumber $\mathrm{CD} 4+\mathrm{T}$ cells in actively demyelinating lesions. Several expanded clones of CD8+ T cell have been found within MS lesions and some of these clones persist for many years in the CSF and blood of the patients [97]. Additionally, CD8+ T cells have been found in increased numbers proximal to demyelinated axons in the CNS, pointing to their active involvement in the inflammatory process [98]. Biopsy samples from early stage MS patients have revealed extensive CD8+ T cell infiltration in the cortex [99], which 
suggests a role in the initiation of MS. Interestingly, treatment of MS using anti-CD4 did not eliminate IFN- $\gamma$-producing primed Thl cells and provided no clinical benefit [100], whilst broader depletion of both CD4+ and CD8+ T cells using anti-CD52 resulted in reduced disability and risk of relapse [101]. The way in which CD8+ T cells act to exacerbate EAE is most likely due to the contribution of proinflammatory subsets such as the Tcl and Tc17 cell. This is supported by the fact that IFN- $\gamma$ and IL-17-producing CD8+ T cells specific for apoptotic $\mathrm{T}$ cell-associated self-epitopes are significantly increased in the CSF of MS patients compared to healthy controls [102]. Further, IL-17A secretion by Tc17 cells has been shown to promote Th17-mediated induction of EAE [103], and Tc17 cells are present within active MS lesions [104]. Taken together, data indicate that CD8+ T cells with strong inflammatory potential are recruited into the CNS during MS, where they contribute to the pathophysiology of the disease.

2.3. Regulatory T Cells. Treg cells are regarded as the most potent immunomodulators of the adaptive immune system, where they act to suppress the action of effector $\mathrm{T}$ cells and maintain immune homeostasis [105]. Among other markers, Treg cells express CD4, the IL- 2 receptor $\alpha$-chain (CD25), and the forkhead box protein 3 transcription factor (FoxP3). Myelin-specific T cells are able to migrate to, and accumulate within, the CNS of animals with EAE [106, 107], and entry into the recovery phase marks a significant increase in FoxP3+ cell numbers to levels higher than those in the periphery (e.g., lymph nodes) [108]. Treg cells may inhibit the action of CD4+ cells through cell-to-cell contact-dependent mechanisms resulting in disruption of T cell receptor (TCR-) induced proliferation and reduced transcription of IL-2 [109]. This would have a significant impact on the immune response as IL-2 functions to regulate $\mathrm{T}$ cell cycle progression and differentiation into the various effector T cell subtypes [110]. Treg cell-mediated $\mathrm{T}$ cell suppression is visible both in vitro, where Treg cells have been reported to inhibit the prolifera-

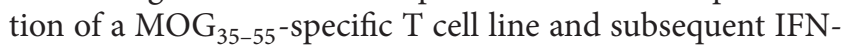
$\gamma$ production, and in vivo, where adoptive transfer has been shown to suppress spontaneous EAE induced by $\mathrm{MOG}_{35-55}$ [109]. The cytokines IL-10, IL-35, and transforming growth factor- (TGF-) $\beta$ produced by Treg cells have also been cited as possible means by which Treg cells exert their inhibitory function [111, 112]. The anti-inflammatory cytokine IL-35 is perhaps the least explored and has been shown to inhibit effector T cell proliferation and Th17 differentiation. Further, IL-35 is known to suppress a range of autoimmune diseases $[113,114]$, and adoptive transfer of IL-35-producing Treg cells protects mice from developing EAE [115]. It is interesting to note that several studies have demonstrated that Treg cells are dysfunctional in both EAE and MS, and their impaired immunosuppressive capacity may be key in disease pathogenesis [116-118].

The mechanisms involved in recovery from EAE and remission in MS are somewhat speculative, but a shift from a predominantly proinflammatory cell infiltrate to one characterised by increased migration of immunosuppressive
Treg cells is likely to play a major role. Remission in RRMS has been shown to correspond with increased proportions of FoxP3+ Treg cells in the blood [119, 120]; however, FoxP3+ cells are present in very low numbers within MS lesions, and this appears independent of disease activity [121]. In EAE, a proportion of FoxP3+ Treg cells are known to arise from neuron-induced conversion from encephalitogenic $\mathrm{T}$ cells and are able to effectively control CNS inflammation [122]. Recovery from EAE is associated with an accumulation of antigen-specific FoxP3+ Treg cells into the CNS, which are able to suppress the production of IFN- $\gamma$ by MOG-sensitised $\mathrm{T}$ cells in coculture [108]. The immunosuppressive action of Treg cell cytokines IL-10 [123] and TGF- $\beta$ [124] on Th1 cell proliferation and function is perhaps the most likely explanation for the concurrent decrease in the presence of CD4+ cells in the CNS. Interestingly, a recently identified FoxP3 negative subtype of Treg cells characterised by the expression of the transcription factor FoxA1 has also been shown to reduce the incidence, clinical scores, and severity of CNS inflammation in EAE following adoptive transfer. FoxA1 expression in CD4+ cells was shown to confer this suppressive function, through caspase- 3 associated apoptosis of activated T cells. Further, IFN- $\beta$, a common treatment for MS, was demonstrated to induce the differentiation and function of the FoxA1 Treg cell subtype, suggesting a possible FoxA1-mediated mechanism for the efficacy of IFN$\beta$ treatment [125]. Collectively, it can be seen that Treg cells are likely to play a central role in the suppression of both disease initiation and the function of autoreactive $\mathrm{T}$ cells; however, a comprehensive characterisation of the mechanism by which this is accomplished is warranted.

\section{Involvement of B Lymphocytes}

$B$ cells function as part of the adaptive immune response, where they predominantly mediate humoral immunity. Mature $\mathrm{B}$ cells are characterised by high expression of CD45R and CD19 [126] and have critical roles as both positive and negative regulators of immunity through antibody production, antigen presentation, and the production of cytokines. In EAE, B cells contribute to demyelination through the production of anti-myelin antibodies following differentiation into plasma cells. However, they have also been shown to have a protective function via downregulation of inflammation and the opsonisation of myelin debris which facilitates clearance by phagocytic cells $[127,128]$. IgG and IgM have been found in $50-75 \%$ of MS patients in acute, chronic active, and chronic inactive lesions and this appears independent of disease duration, clinical disease, or staging. Double immunofluorescence staining showed that IgG and IgM accumulate on axons and oligodendrocytes and are colocalised with complement in demyelinated areas [129]. Lisak et al. demonstrated that B cells isolated from RRMS patients secrete one or more factors toxic to oligodendrocytes, suggesting a pathogenic function in MS [130]. Cytokine production by B cells also accounts in part for their paradoxical role; $B$ cells primed by Th1 cells secrete proinflammatory cytokines including IFN- $\gamma$, IL-12, and $\mathrm{TNF} \alpha$, whilst $\mathrm{B}$ cells primed 
by Th 2 cells secrete cytokines of a more anti-inflammatory nature, such as IL-4 and IL-13 $[131,132]$.

A regulatory role of $B$ cells in EAE was suggested by studies utilising B-cell deficient ( $\mu \mathrm{MT}$ ) mice, which failed to spontaneously recover unlike their WT counterparts [133]. Recently, there has been a focus on the use of anti-CD20 to deplete $\mathrm{B}$ cells and examine their functional role in EAE. Administration of anti-CD20 prior to EAE induction was shown to induce a substantial exacerbation of disease severity, as well as increased infiltration of encephalitogenic T cells into the CNS [134]. This was attributed to a loss of antiinflammatory IL-10 production, which was previously shown to be necessary for the regulatory function of $\mathrm{B}$ cells in EAE [135]. In addition to IL-10, IL-35 produced by B cells is vital for their protective role; a recent study has shown that mice with B cell-specific loss of IL-35 expression lost their ability to recover from EAE [136]. Another possible mechanism by which $B$ cells regulate EAE independent of IL-10 is via the induction of Treg cell regulation. Regardless of the method used, B cell depletion results in a reduction of peripheral Treg cells $[137,138]$. Ray et al. proposed a role for glucocorticoid-induced TNF receptor family-related protein (GITR) as a mechanism by which B cells induce Treg cell proliferation. The study also showed, in contradiction to previous studies citing IL-10 as the primary mechanism of $B$ cell-mediated suppression of EAE, that expression of GITR, but not IL-10, is required for recovery from EAE [139]. Abundant evidence exists for a protective or regulatory role of B cells in EAE; however, further research is needed to ascertain the mechanisms underlying this and whether it can be applied to the treatment of MS.

Conversely, evidence also exists for a pathogenic role of $\mathrm{B}$ cells in EAE. Monson et al. used an anti-CD20 antibody to deplete B cells prior to EAE onset and saw a significant suppression of disease onset [140]. Numerous studies utilising anti-CD20 in established EAE have also shown an attenuation of disease severity. This was associated with less severe CNS inflammation and a reduction in MOG-specific Thl and Th17 cells, suggesting a role for $\mathrm{B}$ cells in antigen presentation and CD4+ T cell activation [134, 138]. Further, Barr et al. (2012) have linked the pathogenicity of B cells in EAE with the production of IL-6. B cells from mice with EAE secrete elevated levels of IL-6 in comparison with naive controls, and mice in which B cell-specific IL-6 has been inhibited show less severe clinical disease than mice retaining full $\mathrm{B}$ cell function. An IL-6 driven mechanism for B cell pathogenesis may also operate in MS, as B cells isolated from patients with RRMS show elevated levels of IL-6 production compared to those from healthy controls [141]. Taken together, data suggest that $\mathrm{B}$ cells, along with their regulatory role in EAE, are vital players in its onset and progression.

\section{Involvement of Natural Killer Cells}

NK cells are major effector cells of innate immunity, where they form the first line of defence against an array of pathogens and tumour cells [142], and regulate the generation of $\mathrm{T}$ cell immunity [143]. Immunohistochemical and flow cytometric analyses have revealed that NK cells account for approximately $17 \%$ of total infiltrating inflammatory cells in the CNS of mice at the clinical peak of EAE [144], and the majority of evidence suggests a protective role for NK cells in CNS inflammation. IL-2 coupled with an anti-IL-2 monoclonal antibody was shown to dramatically expand NK cells in both the periphery and the CNS, and this leads to an attenuation of CNS inflammation and neurological deficits in SJL mice with EAE [145]. Studies examining the effects of NK cell depletion demonstrate that increased severity of EAE is related to an absence of NK cell-mediated killing of myelin antigen-specific encephalitogenic T cells $[146,147]$. Further, mice deficient in CXCR1, a neuronal chemokine receptor involved in NK cell recruitment into the CNS, were found to have increased EAE-related mortality and severity of inflammatory lesions [148]. Interestingly, depletion of NK cells has also been shown to ameliorate clinical EAE; however, this is suggested to result from an absence of NK cellmediated regulation of $\mathrm{T}$ cell immunity leading to a decrease in total lymphocytes reaching the CNS [149]. The mechanism by which NK cell function leads to a diminution of EAE is largely unexplored but has recently been linked to IgGinduced induction of Treg cells and subsequent suppression of IFN- $\gamma$ and IL-17 production by autoreactive T cells [150]. The production of protective neurotrophic factors by NK cells (along with T cells) has also been cited and appears to support recovery of lesioned spinal motoneurons in EAE [151]. Taken together, it is clear that NK cells are an important regulator of immunity during EAE.

The role of NK cells in MS is also unclear; however, evidence suggests that they may be somewhat dysfunctional in such a context. Hamann et al. showed that NK cell frequency in the CSF during MS is significantly decreased compared to the blood, and that these central NK cells display an immature phenotype [152]. NK cell functional activity is also significantly lower in RRMS patients, which is especially apparent immediately preceding the development of both new and enlarging active lesions [153]. RRMS patients also display significantly diminished cytokine-driven accumulation of IFN- $\gamma$-producing CD56 $6_{\text {bright }}$ NK cells in the blood, a marker for NK cells possessing increased regulatory function [154]. Interestingly, PPMS and SPMS patients show increased percentages of CD56 $6_{\mathrm{dim}} \mathrm{NK}$ cells in the blood, which points to an upregulation of NK cells possessing increased cytotoxic, rather than immunoregulatory function [155]. Further, IFN$\beta$, a standard treatment for RRMS, has been shown to expand CD56 bright immunoregulatory NK cells [156] and increases the proportion of NK cells in the active phase of the cell cycle [157]. Whether NK cells are directly involved in the therapeutic effect of IFN- $\beta$ treatment is not known. Treatment with daclizumab, a humanized neutralizing anti-CD25 antibody, also selectively expands and activates CD56 bright cells and correlates with an inhibition of MS brain lesion activity and a contraction of absolute T cell numbers [158, 159]. Similarly, patients with SPMS that show clinical response to mitoxantrone treatment are associated with not only persistent NK cell enrichment but also increased NK cell maturation [160]. The fact that successful immunomodulatory therapies appear to correlate with a rescue of NK cell function in MS patients 
suggests a regulatory role for NK cells in MS; however, the exact mechanisms by which this is accomplished remain undefined.

\section{Involvement of Macrophages and Immune-Like Glial Cells}

5.1. Macrophages/Microglia. Despite being commonly conceptualised as a T cell-mediated disease, the CNS of both MS patients and EAE models is also characterised by activation of resident microglia, as well as extensive infiltration of monocyte-derived macrophages [161-163]. Recent studies have demonstrated that monocyte-derived macrophages and microglia are functionally distinct populations [164] with unique origins; macrophages develop from self-renewing hematopoietic stem cells in the bone marrow via blood monocyte intermediates, whereas microglia are derived from hematopoietic cells in the yolk sac that migrate into the CNS prior to formation of the BBB [165]. During EAE, activated macrophages within CNS lesion sites were historically difficult to distinguish from activated microglia as both appear similar histologically and share similar antigenic markers, notably ionized calcium-binding adapter protein (IBA-1), major histocompatibility complex class II (MHC II), CXCR1, and CD11b [163, 166, 167]. Early studies used CD45 to distinguish between macrophages and microglia, a method where resident microglia are separated from CD $45^{\text {hi }}$ macrophages in haematogenous preparations based on comparatively low expression of CD45 [168, 169]. Recently, however, it has become possible to distinguish between resident microglia and blood-derived macrophages using chimeric mice, whereby bone marrow (BM) cells of naive mice are replaced by donor BM cells containing mismatched-MHC or fluorescently labelled myeloid cells [170, 171]. Using this method, it has been shown that during EAE, a subpopulation of microglial cells became activated in the CNS in the early stages of disease, before clinical symptoms and before the infiltration of peripheral monocytes/macrophages into the CNS [163]. Although suggestive of an active role for microglia in the pathogenesis of EAE, to the best of our knowledge, the differential functional role of microglia and blood-derived macrophages in EAE and MS has not been elucidated to date.

The consensus is that macrophages/microglia play a pathogenic role in both EAE and MS. Bhasin et al. revealed that the timing of macrophage/microglial activation is critical for the progression of EAE. Macrophage inhibitory factor was used to inhibit macrophage/microglial activation and showed that intervention prior to disease induction had only modest effects on EAE progression, whilst intervention at EAE onset significantly ameliorated disease symptoms [172]. Strong correlations have also been found between macrophage infiltration and progression to paralytic EAE, further reinforcing a role for macrophages/microglia in latestage disease [162]. Similar studies involving inactivation of macrophages/microglia in established EAE have been achieved through targeting estrogen receptor $\beta$ [173] and through the use of microRNA-124 [174], both resulting in ameliorated disease severity and enhanced recovery.
Further subtypes of macrophage/microglia exist, including the predominantly proinflammatory M1 cell (iNOS+) which secretes cytokines including TNF- $\alpha$ and IL- $1 \beta$ and the M2 cell (Arg1+), which is anti-inflammatory in nature and is associated with the secretion of IL-10 [175-177]. Unique stimuli endow macrophages/microglia with their phenotype and effector function. Ding et al. first showed that lipopolysaccharides and the proinflammatory cytokine IFN- $\gamma$ promote differentiation of M1 cells [178], whilst differentiation into the M2 subtype is promoted in an antiinflammatory environment containing IL-4 and IL-13 [179]. M1 and M2 cells have been shown to predominate differentially during the course of EAE, with M1 cells contributing to the establishment of early inflammation in EAE [180]. Indeed, the presence of $\mathrm{M} 1$ cells in inflammatory lesions appears to correlate with increased EAE severity, whilst increased M2 cell levels are associated with ameliorated clinical disease and a resolution of inflammation [180-182]. Recent studies have shown that suppression of CNS accumulation of M1 macrophages through conditional ablation of astroglial CCL2 reduces disease severity and preserves axons in EAE [183]. Additionally, adoptive transfer of IL-4-activated M2 cells mitigates clinical disease and inhibits $\mathrm{CD} 4+\mathrm{T}$ cell activation in mice with EAE [184]. Further research is needed to accurately ascertain the influence of macrophage/microglial subtypes in neuroinflammation associated with EAE and whether their action may provide a basis for the development of novel immunotherapeutics in MS.

5.2. Astrocytes. Astrocytes perform an array of homeostatic functions within the CNS, including maintenance of the BBB and modulation of neuronal connections, and are believed to be involved in intercellular communication. Astrocytes have also been implicated in the development of EAE; however, their exact role in CNS inflammation is somewhat unclear due to conflicting studies. Astrocytes are known to be critical in the orchestration of leukocyte recruitment during autoimmune-induced CNS inflammation [185] and are thus vital to the development of EAE. Accumulations of hypertrophic, highly glial fibrillary acidic protein (GFAP) positive astroglia are prominent in the spinal cord during EAE [186], yet whether they serve to positively or negatively modulate disease progression is unknown. Evidence for an aggravatory role has been well demonstrated by studies testing inactivation of the key astroglial transcription factor nuclear factor-kappa B (NF- $\kappa \mathrm{B})$. Inhibition of astroglial NF$\kappa \mathrm{B}$ leads to improved functional outcomes in EAE [187], as well as reduced infiltration of proinflammatory $\mathrm{T}$ cells in acute EAE, reduced numbers of macrophages/microglia in chronic EAE, and increased remyelination [188]. The timing of the astrocytic contribution to EAE pathophysiology is not well established; however, astrocytic responses have been shown to coincide with early inflammation and axonal injury [189].

Paradoxically, evidence also exists to suggest a protective role for astrocytes in EAE and MS. Astrocytes expressing the radial-glia cell marker brain lipid binding protein are evident in high numbers within early MS lesions but are significantly 
less present in chronic lesions seen in long-term sufferers [190]. Wang et al. used transgenic C57BL/6 mice selectively lacking the astrocytic Fas ligand to demonstrate the importance of astrocytes in the control of autoreactive T cells in the CNS of mice with EAE. These mice failed to induce apoptosis of Fas+ CD4+ T cells and did not show an increase in Treg cell numbers beyond the clinical peak of the control group [191], an otherwise common observation in the recovery phase of EAE [108]. Loss of astrocytic leptin signalling has also been shown to have aggravating effects on EAE, with leptin receptor knockout mice recording significantly higher clinical scores than control animals, which was accompanied by increased CD4+ cell infiltration and demyelination [192]. Further, inhibiting the activity of astrocytes in established EAE has been shown to affect the nature of immune cell infiltration and subsequent disease severity. Inhibition of reactive astrocytosis produced increased clinical scores, as well as a substantial increase in myeloid cell infiltration (predominantly macrophages); however, there was no significant change in $\mathrm{T}$ cell infiltration when compared to control mice [193]. Astrocytes are also believed to play a role in neuroprotection, and inhibition of IFN $-\gamma$ signalling to astrocytes increases demyelination at the acute peak of EAE, which is followed by diminished clinical remission, increased mortality, and sustained astrocyte activation within the grey matter at later stages of the disease [194]. Taken together, it can be seen that astrocytes play a role in the control of multiple cell types involved in the production of EAE and are therefore likely to be implicated at multiple stages of both EAE and MS.

\section{Oligodendrocytes}

Oligodendrocytes are specialised cells of the CNS that wrap axons with myelin and allow for the efficient conduction of nervous impulses. Oligodendrocyte damage and apoptosis in response to CNS autoimmune inflammation are most widely considered the pathological basis of EAE and MS and are believed to result from the elaboration of proinflammatory mediators and nitric oxide (NO) by activated $\mathrm{T}$ cells, macrophages, and activated glial cells [195]. There is abundant evidence suggesting that NO levels are significantly raised within MS lesions [196, 197], and this has been demonstrated to form an important facet of MS-associated oligodendrocyte damage [198]. Despite this, the molecular mechanisms underlying oligodendrocyte dysfunction and death in MS are poorly understood.

Although traditionally viewed as immune targets secondary to a dysregulated immune reaction, emerging evidence also suggests that oligodendrocytes may actively participate in the neuroimmune network. Protection from the adverse effects of the Th1 cytokine IFN- $\gamma$ has been cited as the mechanism by which pancreatic endoplasmic reticulum kinase (PERK) activation within (re)myelinating oligodendrocytes enhances their survival in $\operatorname{EAE}[199,200]$. The transcription factor interferon regulatory factor 1 (IRF-1) has also been implicated in the pathogenesis of EAE and MS, and transgenic mice with suppressed IRF-1 specifically in oligodendrocytes are protected against EAE and show decreased inflammatory demyelination, as well as oligodendrocyte and axonal preservation. This conveyed protection was related to impaired expression of immune and proapoptotic genes, suggesting that IRF-1 mediates the oligodendrocyte response to CNS inflammation and resulting injury [201].

Remyelination originates from oligodendrocyte precursor cells (OPCs), which may form a reservoir for the differentiation and migration of mature oligodendrocytes into the CNS during demyelinating diseases, such as MS. Spontaneous remyelination is evident in some MS patients, with $60-96 \%$ of global lesion areas remyelinated in $20 \%$ of MS sufferers at autopsy, and is evident in both RRMS and progressive MS cases [202]. The adult mammalian CNS contains glial precursor cells that express the NG2 proteoglycan, which are known to descend from OPCs in the perinatal CNS. NG2+ cells generate myelinating oligodendrocytes and a limited number of astrocytes to the postnatal brain in EAE [203]. Interestingly, NG2+ cells and mature oligodendrocytes are decreased within areas of subpial cortical demyelination in chronic but not early stage MS [204]. Höftberger et al. have previously proposed that oligodendrocyte loss in later stage MS results from impaired differentiation, migration, and activation capacity of precursor cells [205]. Replenishing the oligodendrocyte precursor pool through intraventricular injection of OPCs derived from human embryonic stem cells [206], or of neural stem cells primed to differentiate into OPCs [207], has been shown to abrogate clinical EAE in mice. Further, Kim and colleagues found that following injection of OPCs, there was subsequent generation of CD45+ cells (a marker for microglia/macrophages), an accumulation of inflammatory cells in the subarachnoid space, and increased numbers of Treg cells in the spinal cord and spleen, suggesting an influence of OPCs on additional immune cell types which may have contributed to the observed decrease in EAE severity [206].

The mechanisms underlying the failure of OPCs to remyelinate damaged axons in MS are relatively unknown. NG2 + cells appear to compensate for demyelination in early EAE (20 days after induction); however, numbers of NG2+ cells and mature oligodendrocytes are strongly diminished in the cerebral cortex in late-stage disease (39 days after induction) [208]. Animal models of EAE suggest that OPCs rather than mature oligodendrocytes are responsible for remyelination in MS, and OPCs have been noted to be significantly more susceptible to injury than mature oligodendrocytes in the context of actively demyelinating MS lesions and in vitro stress conditions [209]. Kang et al. have previously reported that inhibition of IL-17 receptor signalling in neuroectodermal CNS resident cells (neurons, astrocytes, and oligodendrocytes) attenuates the severity of EAE in mice [185]. IL-17-mediated disease exacerbation was recently linked to NG2+ cells, which have been cited as the major CNS cellular target of IL-17 in EAE, suggesting a direct relationship between inflammation and neurodegeneration in MS [210]. Both EAE and MS are associated with an inhibition of OPC differentiation into mature oligodendrocytes capable of remyelination and disease remission, and 
approaches targeting the rectification of this defect may offer a regenerative approach to the treatment of MS.

\section{Conclusions}

It is well established that EAE is induced via autoimmune attack on myelin, leading to inflammatory demyelination and further neurodegeneration. Central aspects concerning the pathogenesis of MS have become highly debated in recent times, especially concerning its underlying aetiology and initiating events. There is nevertheless a broad selection of parallels that may be drawn concerning immune and glial contributions to the pathophysiology of both conditions. Whether an autoimmune mechanism underlies MS is unknown; however, demyelination has an undeniable link to inflammation. This is a pathogenically complex process resulting from the interaction of multiple cell types with encephalitogenic and/or regulatory potential and the immunomodulatory factors they produce (Figure 1). Emerging discoveries concerning different subsets within each cell population and the differential role they may play in the various stages of disease make it difficult to assess their exact role in EAE and MS, with some studies producing conflicting reports. As such, future research is needed to address the specific role of different immune and glial cell subsets in the local inflammatory microenvironment within the CNS longitudinally, which may result in novel therapeutic strategies for MS.

\section{Conflict of Interests}

The authors report no potential conflict of interests for this paper.

\section{Acknowledgments}

This work was partially supported by a grant from the National Health and Medical Research Council of Australia to Gila Moalem-Taylor. They thank Chamini Perera for going through the paper.

\section{References}

[1] L. A. Rolak, "Multiple sclerosis: it's not the disease you thought it was," Clinical Medicine \& Research, vol. 1, no. 1, pp. 57-60, 2003.

[2] G. Faraco, L. Cavone, and A. Chiarugi, "The therapeutic potential of HDAC inhibitors in the treatment of multiple sclerosis," Molecular Medicine, vol. 17, no. 5-6, pp. 442-447, 2011.

[3] V. Browning, M. Joseph, and M. Sedrak, "Multiple sclerosis: a comprehensive review for the physician assistant," Journal of the American Academy of Physician Assistants, vol. 25, no. 8, pp. 2429, 2012.

[4] M. M. Goldenberg, "Multiple sclerosis review," $P$ and T, vol. 37, no. 3, pp. 175-184, 2012.

[5] J. H. Noseworthy, C. Lucchinetti, M. Rodriguez, and B. G. Weinshenker, "Multiple sclerosis," The New England Journal of Medicine, vol. 343, no. 13, pp. 938-952, 2000.

[6] G. C. Ebers, "Natural history of multiple sclerosis," Neurology in Practice, vol. 71, no. 2, pp. iil6-ii19, 2001.
[7] F. D. Lublin, S. C. Reingold, J. A. Cohen et al., "Defining the clinical course of multiple sclerosis: the 2013 revisions," Neurology, vol. 83, no. 3, pp. 278-286, 2013.

[8] F. D. Lublin and S. C. Reingold, "Defining the clinical course of multiple sclerosis: results of an international survey," Neurology, vol. 46, no. 4, pp. 907-911, 1996.

[9] R. A. Rudick, “Disease-modifying drugs for relapsing-remitting multiple sclerosis and future directions for multiple sclerosis therapeutics," Archives of Neurology, vol. 56, no. 9, pp. 10791084, 1999.

[10] T. M. Rivers, D. H. Sprunt, and G. P. Berry, “Observations on attempts to produce acute disseminated encephalomyelitis in monkeys," The Journal of Experimental Medicine, vol. 58, no. 1, pp. 39-53, 1933.

[11] A. G. Baxter, "The origin and application of experimental autoimmune encephalomyelitis," Nature Reviews Immunology, vol. 7, no. 11, pp. 904-912, 2007.

[12] L. Steinman and S. S. Zamvil, "How to successfully apply animal studies in experimental allergic encephalomyelitis to research on multiple sclerosis," Annals of Neurology, vol. 60, no. 1, pp. 12-21, 2006.

[13] I. Mendel, N. Kerlero De Rosbo, and A. Ben-Nun, "A myelin oligodendrocyte glycoprotein peptide induces typical chronic experimental autoimmune encephalomyelitis in $\mathrm{H}-2 \mathrm{~b}$ mice: fine specificity and $\mathrm{T}$ cell receptor $\mathrm{Y} \beta$ expression of encephalitogenic T cells," European Journal of Immunology, vol. 25, no. 7, pp. 1951-1959, 1995.

[14] J. Goverman, A. Woods, L. Larson, L. P. Weiner, L. Hood, and D. M. Zaller, "Transgenic mice that express a myelin basic proteinspecific T cell receptor develop spontaneous autoimmunity," Cell, vol. 72, no. 4, pp. 551-560, 1993.

[15] H. Waldner, M. J. Whitters, R. A. Sobel, M. Collins, and V. K. Kuchroo, "Fulminant spontaneous autoimmunity of the central nervous system in mice transgenic for the myelin proteolipid protein-specific T cell receptor," Proceedings of the National Academy of Sciences of the United States of America, vol. 97, no. 7, pp. 3412-3417, 2000.

[16] L.-H. Guo and H. J. Schluesener, "Lesional accumulation of $\mathrm{P}_{2} \mathrm{X}_{4}$ receptor ${ }^{+}$macrophages in rat CNS during experimental autoimmune encephalomyelitis," Neuroscience, vol. 134, no. 1, pp. 199-205, 2005.

[17] J. A. Encinas, M. B. Lees, R. A. Sobel et al., "Identification of genetic loci associated with paralysis, inflammation and weight loss in mouse experimental autoimmune encephalomyelitis," International Immunology, vol. 13, no. 3, pp. 257-264, 2001.

[18] P. K. Stys, G. W. Zamponi, J. Van Minnen, and J. J. G. Geurts, "Will the real multiple sclerosis please stand up?" Nature Reviews Neuroscience, vol. 13, no. 7, pp. 507-514, 2012.

[19] A. P. D. Henderson, M. H. Barnett, J. D. E. Parratt, and J. W. Prineas, "Multiple sclerosis: distribution of inflammatory cells in newly forming lesions," Annals of Neurology, vol. 66, no. 6, pp. 739-753, 2009.

[20] R. M. Ransohoff, "Animal models of multiple sclerosis: the good, the bad and the bottom line," Nature Neuroscience, vol. 15, no. 8, pp. 1074-1077, 2012.

[21] K. G. Su, G. Banker, D. Bourdette, and M. Forte, "Axonal degeneration in multiple sclerosis: the mitochondrial hypothesis," Current Neurology and Neuroscience Reports, vol. 9, no. 5, pp. 411-417, 2009.

[22] A. Ben-Nun, H. Wekerle, and I. R. Cohen, "The rapid isolation of clonable antigen-specific $\mathrm{T}$ lymphocyte lines capable of 
mediating autoimmune encephalomyelitis," European Journal of Immunology, vol. 11, no. 3, pp. 195-199, 1981.

[23] T. A. Yednock, C. Cannon, L. C. Fritz, F. Sanchez-Madrid, L. Steinmant, and N. Karin, "Prevention of experimental autoimmune encephalomyelitis by antibodies against $\alpha 4 \beta 1$ integrin," Nature, vol. 356, no. 6364, pp. 63-66, 1992.

[24] D. S. Skundric, C. Kim, H. Y. Tse, and C. S. Raine, "Homing of $\mathrm{T}$ cells to the central nervous system throughout the course of relapsing experimental autoimmune encephalomyelitis in Thy1 congenic mice," Journal of Neuroimmunology, vol. 46, no. 1-2, pp. 113-121, 1993.

[25] J. M. Frischer, S. Bramow, A. Dal-Bianco et al., "The relation between inflammation and neurodegeneration in multiple sclerosis brains," Brain, vol. 132, no. 5, pp. 1175-1189, 2009.

[26] G. Androdias, R. Reynolds, M. Chanal, C. Ritleng, C. Confavreux, and S. Nataf, "Meningeal T cells associate with diffuse axonal loss in multiple sclerosis spinal cords," Annals of Neurology, vol. 68, no. 4, pp. 465-476, 2010.

[27] B. N. Dittel, "CD4 T cells: balancing the coming and going of autoimmune-mediated inflammation in the CNS," Brain, Behavior, and Immunity, vol. 22, no. 4, pp. 421-430, 2008.

[28] H. Körner, A. L. Goodsall, F. A. Lemckert et al., "Unimpaired autoreactive T-cell traffic within the central nervous system during tumor necrosis factor receptor-mediated inhibition of experimental autoimmune encephalomyelitis," Proceedings of the National Academy of Sciences of the United States of America, vol. 92, no. 24, pp. 11066-11070, 1995.

[29] H. Körner, F. A. Lemckert, G. Chaudhri, S. Etteldorf, and J. D. Sedgwick, "Tumor necrosis factor blockade in actively induced experimental autoimmune encephalomyelitis prevents clinical disease despite activated $\mathrm{T}$ cell infiltration to the central nervous system," European Journal of Immunology, vol. 27, no. 8, pp. 1973-1981, 1997.

[30] D. S. Riminton, H. Körner, D. H. Strickland, F. A. Lemckert, J. D. Pollard, and J. D. Sedgwick, "Challenging cytokine redundancy: Inflammatory cell movement and clinical course of experimental autoimmune encephalomyelitis are normal in lymphotoxindeficient, but not tumor necrosis factor-deficient, mice," Journal of Experimental Medicine, vol. 187, no. 9, pp. 1517-1528, 1998.

[31] A. R. Glabinski, B. Bielecki, J. A. Kawczak, V. K. Tuohy, K. Selmaj, and R. M. Ransohoff, "Treatment with soluble tumor necrosis factor receptor (sTNFR):Fc/p80 fusion protein ameliorates relapsing-remitting experimental autoimmune encephalomyelitis and decreases chemokine expression," Autoimmunity, vol. 37, no. 6-7, pp. 465-471, 2004.

[32] H. P. Eugster, K. Frei, R. Bachmann, H. Bluethmann, H. Lassmann, and A. Fontana, "Severity of symptoms and demyelination in MOG-induced EAE depends on TNFR1," European Journal of Immunology, vol. 29, no. 2, pp. 626-632, 1999.

[33] K. Selmaj, W. Papierz, A. Glabinski, and T. Kohno, "Prevention of chronic relapsing experimental autoimmune encephalomyelitis by soluble tumor necrosis factor receptor I," Journal of Neuroimmunology, vol. 56, no. 2, pp. 135-141, 1995.

[34] N. Hövelmeyer, Z. Hao, K. Kranidioti et al., "Apoptosis of oligodendrocytes via fas and TNF-R1 is a key event in the induction of experimental autoimmune encephalomyelitis," Journal of Immunology, vol. 175, no. 9, pp. 5875-5884, 2005.

[35] K. Frei, H.-P. Eugster, M. Bopst, C. S. Constantinescu, E. Lavi, and A. Fontana, "Tumor necrosis factor $\alpha$ and lymphotoxin $\alpha$ are not required for induction of acute experimental autoimmune encephalomyelitis," Journal of Experimental Medicine, vol. 185 , no. 12 , pp. 2177-2182, 1997.
[36] J. Liu, M. W. Marino, G. Wong et al., “TNF is a potent antiinflammatory cytokine in autoimmune-mediated demyelination," Nature Medicine, vol. 4, no. 1, pp. 78-83, 1998.

[37] H. Körner, D. S. Riminton, D. H. Strickland, F. A. Lemckert, J. D. Pollard, and J. D. Sedgwick, "Critical points of tumor necrosis factor action in central nervous system autoimmune inflammation defined by gene targeting," Journal of Experimental Medicine, vol. 186, no. 9, pp. 1585-1590, 1997.

[38] G. Kassiotis, M. Pasparakis, G. Kollias, and L. Probert, “TNF accelerates the onset but does not alter the incidence and severity of myelin basic protein-induced experimental autoimmune encephalomyelitis," European Journal of Immunology, vol. 29, no. 3, pp. 774-780, 1999.

[39] H. Batoulis, M. S. Recks, F. O. Holland, F. Thomalla, R. O. Williams, and S. Kuerten, "Blockade of tumour necrosis factor$\alpha$ in experimental autoimmune encephalomyelitis reveals differential effects on the antigen-specific immune response and central nervous system histopathology," Clinical and Experimental Immunology, vol. 175, no. 1, pp. 41-48, 2014.

[40] "TNF neutralization in MS: results of a randomized, placebocontrolled multicenter study. The Lenercept Multiple Sclerosis Study Group and The University of British Columbia MS/MRI Analysis Group," Neurology, vol. 53, no. 3, pp. 457-465, 1999.

[41] H. S. Panitch, R. L. Hirsch, J. Schindler, and K. P. Johnson, "Treatment of multiple sclerosis with gamma interferon: exacerbations associated with activation of the immune system," Neurology, vol. 37, no. 7, pp. 1097-1102, 1987.

[42] T. Renno, V. Taupin, L. Bourbonnière et al., "Interferon- $\gamma$, in progression to chronic demyelination and neurological deficit following acute EAE," Molecular and Cellular Neurosciences, vol. 12, no. 6, pp. 376-389, 1998.

[43] Á. C. Murphy, S. J. Lalor, M. A. Lynch, and K. H. G. Mills, "Infiltration of Th1 and Th17 cells and activation of microglia in the CNS during the course of experimental autoimmune encephalomyelitis," Brain, Behavior, and Immunity, vol. 24, no. 4, pp. 641-651, 2010.

[44] S. Kanakasabai, W. Chearwae, C. C. Walline, W. Iams, S. M. Adams, and J. J. Bright, "Peroxisome proliferator-activated receptor $\delta$ agonists inhibit T helper type 1 (Th1) and Th17 responses in experimental allergic encephalomyelitis," Immunology, vol. 130, no. 4, pp. 572-588, 2010.

[45] I. A. Ferber, S. Brocke, C. Taylor-Edwards et al., "Mice with a disrupted IFN- $\gamma$ gene are susceptible to the induction of experimental autoimmune encephalomyelitis (EAE)," Journal of Immunology, vol. 156, no. 1, pp. 5-7, 1996.

[46] D. O. Willenborg, S. Fordham, C. C. A. Bernard, W. B. Cowden, and I. A. Ramshaw, "IFN-gamma plays a critical down-regulatory role in the induction and effector phase of myelin oligodendrocyte glycoprotein-induced autoimmune encephalomyelitis," Journal of Immunology, vol. 157, no. 8, pp. 3223-3227, 1996.

[47] A. Billiau, H. Heremans, F. Vandekerckhove et al., "Enhancement of experimental allergic encephalomyelitis in mice by antibodies against IFN- $\gamma$," Journal of Immunology, vol. 140, no. 5, pp. 1506-1510, 1988.

[48] T. T. Duong, J. St. Louis, J. J. Gilbert, F. D. Finkelman, and G. H. Strejan, "Effect of anti-interferon- $\gamma$ and anti-interleukin-2 monoclonal antibody treatment on the development of actively and passively induced experimental allergic encephalomyelitis in the SJL/J mouse," Journal of Neuroimmunology, vol. 36, no. 2-3, pp. 105-115, 1992. 
[49] L. S. Dungan, N. C. McGuinness, L. Boon, M. A. Lynch, and K. H. G. Mills, "Innate IFN- $\gamma$ promotes development of experimental autoimmune encephalomyelitis: a role for NK cells and M1 macrophages," European Journal of Immunology, 2014.

[50] M. P. Crawford, S. X. Yan, S. B. Ortega et al., "High prevalence of autoreactive, neuroantigen-specific $\mathrm{CD} 8^{+} \mathrm{T}$ cells in multiple sclerosis revealed by novel flow cytometric assay," Blood, vol. 103, no. 11, pp. 4222-4231, 2004.

[51] G. Frisullo, V. Nociti, R. Iorio et al., "IL17 and IFN $\gamma$ production by peripheral blood mononuclear cells from clinically isolated syndrome to secondary progressive multiple sclerosis," Cytokine, vol. 44, no. 1, pp. 22-25, 2008.

[52] S. Skurkovich, A. Boiko, I. Beliaeva et al., "Randomized study of antibodies to IFN- $\gamma$ and TNF- $\alpha$ in secondary progressive multiple sclerosis," Multiple Sclerosis, vol. 7, no. 5, pp. 277-284, 2001.

[53] T. R. Mosmann and S. Sad, "The expanding universe of T-cell subsets: Th1, Th2 and more," Immunology Today, vol. 17, no. 3 , pp. 138-146, 1996.

[54] M. Bitan, L. Weiss, I. Reibstein et al., "Heparanase upregulates Th2 cytokines, ameliorating experimental autoimmune encephalitis," Molecular Immunology, vol. 47, no. 10, pp. 18901898, 2010.

[55] G.-X. Zhang, S. Yu, B. Gran, and A. Rostami, "Glucosamine abrogates the acute phase of experimental autoimmune encephalomyelitis by induction of Th2 response," Journal of Immunology, vol. 175, no. 11, pp. 7202-7208, 2005.

[56] R. Liblau, L. Steinman, and S. Brocke, "Experimental autoimmune encephalomyelitis in IL-4-deficient mice," International Immunology, vol. 9, no. 5, pp. 799-803, 1997.

[57] M.-L. Zhao and R. B. Fritz, "Acute and relapsing experimental autoimmune encephalomyelitis in IL-4- and $\alpha / \beta$ T celldeficient C57BL/6 mice," Journal of Neuroimmunology, vol. 87, no. 1-2, pp. 171-178, 1998.

[58] M. Falcone, A. J. Rajan, B. R. Bloom, and C. F. Brosnan, "A critical role for IL-4 in regulating disease severity in experimental allergic encephalomyelitis as demonstrated in IL-4 deficient C57BL/6 mice and BALB/c mice," Journal of Immunology, vol. 160, no. 10, pp. 4822-4830, 1998.

[59] R. Furlan, P. L. Poliani, P. C. Marconi et al., "Central nervous system gene therapy with interleukin- 4 inhibits progression of ongoing relapsing-remitting autoimmune encephalomyelitis in Biozzi AB/H mice," Gene Therapy, vol. 8, no. 1, pp. 13-19, 2001.

[60] R. Furlan, P. L. Poliani, F. Galbiati et al., "Central nervous system delivery of interleukin 4 by a nonreplicative herpes simplex type 1 viral vector ameliorates autoimmune demyelination," Human Gene Therapy, vol. 9, no. 17, pp. 2605-2617, 1998.

[61] V. Fernando, S. Omura, F. Sato et al., "Regulation of an autoimmune model for multiple sclerosis in Th2-biased GATA3 transgenic mice," International Journal of Molecular Sciences, vol. 15, no. 2, pp. 1700-1718, 2014.

[62] E. B. Samoilova, J. L. Horton, and Y. Chen, "Acceleration of experimental autoimmune encephalomyelitis in interleukin-10deficient mice: roles of interleukin-10 in disease progression and recovery," Cellular Immunology, vol. 188, no. 2, pp. 118-124, 1998.

[63] E. Bettelli, M. P. Das, E. D. Howard, H. L. Weiner, R. A. Sobel, and V. K. Kuchroo, "IL-10 is critical in the regulation of autoimmune encephalomyelitis as demonstrated by studies of IL-10- and IL-4-deficient and transgenic mice," Journal of Immunology, vol. 161, no. 7, pp. 3299-3306, 1998.
[64] E. Sloane, A. Ledeboer, W. Seibert et al., "Anti-inflammatory cytokine gene therapy decreases sensory and motor dysfunction in experimental Multiple Sclerosis: MOG-EAE behavioral and anatomical symptom treatment with cytokine gene therapy," Brain, Behavior, and Immunity, vol. 23, no. 1, pp. 92-100, 2009.

[65] D. J. Cua, H. Groux, D. R. Hinton, S. A. Stohlman, and R. L. Coffman, "Transgenic interleukin 10 prevents induction of experimental autoimmune encephalomyelitis," Journal of Experimental Medicine, vol. 189, no. 6, pp. 1005-1010, 1999.

[66] C.-Z. Lu, M. A. Jensen, and B. G. W. Arnason, "Interferon $\alpha$ and interleukin-4-secreting cells in multiple sclerosis," Journal of Neuroimmunology, vol. 46, no. 1-2, pp. 123-128, 1993.

[67] D. Franciotta, E. Zardini, R. Bergamaschi, L. Andreoni, and V. Cosi, "Interferon- $\gamma$ and interleukin-4-producing $\mathrm{T}$ cells in peripheral blood of multiple sclerosis patients," European Cytokine Network, vol. 11, no. 4, pp. 677-681, 2000.

[68] S. A. Brod, L. D. Nelson, M. Khan, and J. S. Wolinsky, "Increased in vitro induced CD4+ and CDs+ T cell IFN- $\gamma$ and CD4+ T cell IL-10 production in stable relapsing multiple sclerosis," International Journal of Neuroscience, vol. 90, no. 3-4, pp. 187202, 1997.

[69] K. Hohnoki, A. Inoue, and C.-S. Koh, "Elevated serum levels of IFN- $\gamma$, IL- 4 and TNF- $\alpha$ /unelevated serum levels of IL-10 in patients with demyelinating diseases during the acute stage," Journal of Neuroimmunology, vol. 87, no. 1-2, pp. 27-32, 1998.

[70] M. D. C. Rodríguez-Sáinz, S. Sánchez-Ramón, C. de Andrés, M. Rodríguez-Mahou, and M. Á. Muñoz-Fernández, “Th1/Th2 cytokine balance and nitric oxide in cerebrospinal fluid and serum from patients with multiple sclerosis," European Cytokine Network, vol. 13, no. 1, pp. 110-114, 2002.

[71] H. H. Hofstetter, S. M. Ibrahim, D. Koczan et al., "Therapeutic efficacy of IL-17 neutralization in murine experimental autoimmune encephalomyelitis," Cellular Immunology, vol. 237, no. 2, pp. 123-130, 2005.

[72] A. Reboldi, C. Coisne, D. Baumjohann et al., " $\mathrm{C}-\mathrm{C}$ chemokine receptor 6-regulated entry of TH-17 cells into the CNS through the choroid plexus is required for the initiation of EAE," Nature Immunology, vol. 10, no. 5, pp. 514-523, 2009.

[73] H. F. McFarland and R. Martin, "Multiple sclerosis: a complicated picture of autoimmunity," Nature Immunology, vol. 8, no. 9, pp. 913-919, 2007.

[74] D. J. Cua, J. Sherlock, Y. Chen et al., "Interleukin-23 rather than interleukin-12 is the critical cytokine for autoimmune inflammation of the brain," Nature, vol. 421, no. 6924, pp. 744748, 2003.

[75] M. A. Kroenke and B. M. Segal, "IL-23 modulated myelinspecific T cells induce EAE via an IFN $\gamma$ driven, IL-17 independent pathway," Brain, Behavior, and Immunity, vol. 25, no. 5, pp. 932-937, 2011.

[76] M. A. Kroenke, S. W. Chensue, and B. M. Segal, "EAE mediated by a non-IFN- $\gamma /$ non-IL-17 pathway," European Journal of Immunology, vol. 40, no. 8, pp. 2340-2348, 2010.

[77] L. Codarri, G. Gyülvészii, V. Tosevski et al., "ROR $\gamma 3 t$ drives production of the cytokine GM-CSF in helper T cells, which is essential for the effector phase of autoimmune neuroinflammation," Nature Immunology, vol. 12, no. 6, pp. 560-567, 2011.

[78] C. L. Langrish, Y. Chen, W. M. Blumenschein et al., "IL-23 drives a pathogenic $\mathrm{T}$ cell population that induces autoimmune inflammation," Journal of Experimental Medicine, vol. 201, no. 2, pp. 233-240, 2005.

[79] A. Jäger, V. Dardalhon, R. A. Sobel, E. Bettelli, and V. K. Kuchroo, "Th1, Th17, and Th9 effector cells induce experimental 
autoimmune encephalomyelitis with different pathological phenotypes," Journal of Immunology, vol. 183, no. 11, pp. 7169-7177, 2009.

[80] I. Gonzalez-García, Y. Zhao, S. Ju et al., "IL-17 signalingindependent central nervous system autoimmunity is negatively regulated by TGF- $\beta$," Journal of Immunology, vol. 182, no. 5, pp. 2665-2671, 2009.

[81] Y. Komiyama, S. Nakae, T. Matsuki et al., "IL-17 plays an important role in the development of experimental autoimmune encephalomyelitis," Journal of Immunology, vol. 177, no. 1, pp. 566-573, 2006.

[82] S. Haak, A. L. Croxford, K. Kreymborg et al., "IL-17A and IL-17F do not contribute vitally to autoimmune neuro-inflammation in mice," The Journal of Clinical Investigation, vol. 119, no. 1, pp. 61-69, 2009.

[83] B. M. Segal, C. S. Constantinescu, A. Raychaudhuri, L. Kim, R. Fidelus-Gort, and L. H. Kasper, "Repeated subcutaneous injections of IL12/23 p40 neutralising antibody, ustekinumab, in patients with relapsing-remitting multiple sclerosis: a phase II, double-blind, placebo-controlled, randomised, dose-ranging study," The Lancet Neurology, vol. 7, no. 9, pp. 796-804, 2008.

[84] V. Brucklacher-Waldert, K. Stuerner, M. Kolster, J. Wolthausen, and E. Tolosa, "Phenotypical and functional characterization of T helper 17 cells in multiple sclerosis," Brain, vol. 132, part 12, pp. 3329-3341, 2009.

[85] L. Durelli, L. Conti, M. Clerico et al., "T-helper 17 cells expand in multiple sclerosis and are inhibited by interferon- $\beta$," Annals of Neurology, vol. 65, no. 5, pp. 499-509, 2009.

[86] H. Kebir, K. Kreymborg, I. Ifergan et al., "Human TH17 lymphocytes promote blood-brain barrier disruption and central nervous system inflammation," Nature Medicine, vol. 13, no. 10, pp. 1173-1175, 2007.

[87] D. M. Gravano and K. K. Hoyer, "Promotion and prevention of autoimmune disease by $\mathrm{CD} 8{ }^{+} \mathrm{T}$ cells," Journal of Autoimmunity, vol. 45, pp. 68-79, 2013.

[88] H. Jiang, S. L. Zhang, and B. Pernis, "Role of CD8+ T cells in murine experimental allergic encephalomyelitis," Science, vol. 256, no. 5060, pp. 1213-1215, 1992.

[89] D.-R. Koh, W.-P. Fung-Leung, A. Ho, D. Gray, H. Acha-Orbea, and T.-W. Mak, "Less mortality but more relapses in experimental allergic encephalomyelitis in CD8-/- mice," Science, vol. 256, no. 5060, pp. 1210-1213, 1992.

[90] D. Sun, J. N. Whitaker, Z. Huang et al., "Myelin antigen-specific $\mathrm{CD} 8+\mathrm{T}$ cells are encephalitogenic and produce severe disease in C57BL/6 mice," Journal of Immunology, vol. 166, no. 12, pp. 7579-7587, 2001.

[91] E. S. Huseby, D. Liggitt, T. Brabb, B. Schnabel, C. Öhlén, and J. Goverman, "A pathogenic role for myelin-specific CD8+ T cells in a model for multiple sclerosis," Journal of Experimental Medicine, vol. 194, no. 5, pp. 669-676, 2001.

[92] M. L. Ford and B. D. Evavold, "Specificity, magnitude, and kinetics of MOG-specific $\mathrm{CD} 8^{+} \mathrm{T}$ cell responses during experimental autoimmune encephalomyelitis," European Journal of Immunology, vol. 35, no. 1, pp. 76-85, 2005.

[93] M. Camara, N. Beyersdorf, H. J. Fischer et al., "CD8+ T cell help is required for efficient induction of EAE in Lewis rats," Journal of Neuroimmunology, vol. 260, no. 1-2, pp. 17-27, 2013.

[94] Q. Luo, Y. Sun, F.-Y. Gong et al., "Blocking initial infiltration of pioneer $\mathrm{CD}^{+} \mathrm{T}$ cells into the CNS via inhibition of SHP2 ameliorates experimental autoimmune encephalomyelitis in mice," British Journal of Pharmacology, vol. 171, no. 7, pp. 17061721, 2013.
[95] M. Bettini, K. Rosenthal, and B. D. Evavold, "Pathogenic MOGreactive $\mathrm{CD}^{+} \mathrm{T}$ cells require MOG-reactive $\mathrm{CD} 4^{+} \mathrm{T}$ cells for sustained CNS inflammation during chronic EAE," Journal of Neuroimmunology, vol. 213, no. 1-2, pp. 60-68, 2009.

[96] T. Leuenberger, M. Paterka, E. Reuter et al., "The role of $\mathrm{CD} 8+\mathrm{T}$ cells and their local interaction with CD4+T cells in myelin oligodendrocyte glycoprotein35-55- induced experimental autoimmune encephalomyelitis," Journal of Immunology, vol. 191, no. 10, pp. 4960-4968, 2013.

[97] C. Skulina, S. Schmidt, K. Dornmair et al., "Multiple sclerosis: Brain-infiltrating CD8+ T cells persist as clonal expansions in the cerebrospinal fluid and blood," Proceedings of the National Academy of Sciences of the United States of America, vol. 101, no. 8, pp. 2428-2433, 2004.

[98] H. Babbe, A. Roers, A. Waisman et al., "Clonal expansions of $\mathrm{CD} 8+\mathrm{T}$ cells dominate the $\mathrm{T}$ cell infiltrate in active multiple sclerosis lesions as shown by micromanipulation and single cell polymerase chain reaction," Journal of Experimental Medicine, vol. 192, no. 3, pp. 393-404, 2000.

[99] C. F. Lucchinetti, B. F. G. Popescu, R. F. Bunyan et al., "Inflammatory cortical demyelination in early multiple sclerosis," The New England Journal of Medicine, vol. 365, no. 23, pp. 2188-2197, 2011.

[100] M. H. G. Rep, B. W. Van Oosten, M. T. L. Roos, H. J. Adèr, C. H. Polman, and R. A. W. Van Lier, "Treatment with depleting CD4 monoclonal antibody results in a preferential loss of circulating naive $\mathrm{T}$ cells but does not affect IFN- $\gamma$ secreting TH1 cells in humans," Journal of Clinical Investigation, vol. 99, no. 9, pp. 2225-2231, 1997.

[101] A. J. Coles, D. A. S. Compston, K. W. Selmaj et al., "Alemtuzumab vs. interferon beta-1a in early multiple sclerosis," The New England Journal of Medicine, vol. 359, no. 17, pp. 1786-1801, 2008.

[102] F. Lolli, H. Martini, A. Citro et al., "Increased CD8+ T cell responses to apoptotic $\mathrm{T}$ cell-associated antigens in multiple sclerosis," Journal of Neuroinflammation, vol. 10, p. 94, 2013.

[103] M. Huber, S. Heink, A. Pagenstecher et al., "IL-17A secretion by CD8+ $\mathrm{T}$ cells supports Th17-mediated autoimmune encephalomyelitis," Journal of Clinical Investigation, vol. 123, no. 1, pp. 247-260, 2013.

[104] J. S. Tzartos, M. A. Friese, M. J. Craner et al., "Interleukin-17 production in central nervous system-infiltrating $\mathrm{T}$ cells and glial cells is associated with active disease in multiple sclerosis," The American Journal of Pathology, vol. 172, no. 1, pp. 146-155, 2008.

[105] M. Kronenberg and A. Rudensky, "Regulation of immunity by self-reactive T cells," Nature, vol. 435, no. 7042, pp. 598-604, 2005.

[106] M. J. McGeachy, L. A. Stephens, and S. M. Anderton, "Natural recovery and protection from autoimmune encephalomyelitis: contribution of CD4+CD25+ regulatory cells within the central nervous system," Journal of Immunology, vol. 175, no. 5, pp. 3025-3032, 2005.

[107] T. Korn, J. Reddy, W. Gao et al., "Myelin-specific regulatory T cells accumulate in the CNS but fail to control autoimmune inflammation," Nature Medicine, vol.13, no. 4, pp. 423-431, 2007.

[108] R. A. O'Connor, K. H. Malpass, and S. M. Anderton, "The inflamed central nervous system drives the activation and rapid proliferation of Foxp3+ regulatory T cells," Journal of Immunology, vol. 179, no. 2, pp. 958-966, 2007.

[109] A. M. Thornton and E. M. Shevach, "Suppressor effector function of CD4+CD25+ immunoregulatory T cells is antigen 
nonspecific," Journal of Immunology, vol. 164, no. 1, pp. 183-190, 2000.

[110] K. A. Smith, "Interleukin-2: inception, impact, and implications," Science, vol. 240, no. 4856, pp. 1169-1176, 1988.

[111] H. Groux, A. O’Garra, M. Bigler et al., "A CD4 ${ }^{+}$T-cell subset inhibits antigen-specific T-cell responses and prevents colitis," Nature, vol. 389, no. 6652, pp. 737-742, 1997.

[112] L. W. Collison, C. J. Workman, T. T. Kuo et al., "The inhibitory cytokine IL-35 contributes to regulatory T-cell function," Nature, vol. 450, no. 7169, pp. 566-569, 2007.

[113] W. Niedbala, X.-Q. Wei, B. Cai et al., "IL-35 is a novel cytokine with therapeutic effects against collagen-induced arthritis through the expansion of regulatory T cells and suppression of Th17 cells," European Journal of Immunology, vol. 37, no. 11, pp. 3021-3029, 2007.

[114] I. Kochetkova, S. Golden, K. Holderness, G. Callis, and D. W. Pascual, "IL-35 stimulation of CD39+ regulatory T cells confers protection against collagen II-induced arthritis via the production of IL-10," Journal of Immunology, vol. 184, no. 12, pp. 7144-7153, 2010.

[115] L. W. Collison, V. Chaturvedi, A. L. Henderson et al., "IL-35mediated induction of a potent regulatory T cell population," Nature Immunology, vol. 11, pp. 1093-1101, 2010.

[116] V. Viglietta, C. Baecher-Allan, H. L. Weiner, and D. A. Hafler, "Loss of functional suppression by CD4+CD25+ regulatory $\mathrm{T}$ cells in patients with multiple sclerosis," Journal of Experimental Medicine, vol. 199, no. 7, pp. 971-979, 2004.

[117] J. Haas, A. Hug, A. Viehöver et al., "Reduced suppressive effect of CD4+CD25high regulatory $\mathrm{T}$ cells on the $\mathrm{T}$ cell immune response against myelin oligodendrocyte glycoprotein in patients with multiple sclerosis," European Journal of Immunology, vol. 35, no. 11, pp. 3343-3352, 2005.

[118] V. Kumar, K. Stellrecht, and E. Sercarz, "Inactivation of T cell receptor peptide-specific CD4 regulatory $\mathrm{T}$ cells induces chronic experimental autoimmune encephalomyelitis (EAE)," Journal of Experimental Medicine, vol. 184, no. 5, pp. 1609-1617, 1996.

[119] D. D. Libera, D. Di Mitri, A. Bergami et al., "T regulatory cells are markers of disease activity in multiple sclerosis patients," PLoS ONE, vol. 6, no. 6, Article ID e21386, 2011.

[120] E. Peelen, J. Damoiseaux, J. Smolders et al., "Th17 expansion in MS patients is counterbalanced by an expanded CD39+ regulatory $\mathrm{T}$ cell population during remission but not during relapse," Journal of Neuroimmunology, vol. 240-241, pp. 97-103, 2011.

[121] B. Fritzsching, J. Haas, F. König et al., "Intracerebral human regulatory $\mathrm{T}$ cells: analysis of $\mathrm{CD} 4+\mathrm{CD} 25+\mathrm{FOXP} 3+\mathrm{T}$ cells in brain lesions and cerebrospinal fluid of multiple sclerosis patients," PLoS ONE, vol. 6, no. 3, Article ID e17988, 2011.

[122] Y. Liu, I. Teige, B. Birnir, and S. Issazadeh-Navikas, "Neuronmediated generation of regulatory $\mathrm{T}$ cells from encephalitogenic T cells suppresses EAE," Nature Medicine, vol. 12, no. 5, pp. 518-525, 2006.

[123] H. Groux, M. Bigler, J. E. de Vries, and M. G. Roncarolo, "Interleukin-10 induces a long-term antigen-specific anergic state in human CD4+ T cells," Journal of Experimental Medicine, vol. 184, no. 1, pp. 19-29, 1996.

[124] J. T. Lin, S. L. Martin, L. Xia, and J. D. Gorham, “TGF- $\beta 1$ uses distinct mechanisms to inhibit IFN- $\gamma$ expression in CD4+ T cells at priming and at recall: Differential involvement of Stat 4 and T-bet," Journal of Immunology, vol. 174, no. 10, pp. 59505958, 2005.
[125] Y. Liu, R. Carlsson, M. Comabella et al., "FoxA1 directs the lineage and immunosuppressive properties of a novel regulatory T cell population in EAE and MS," Nature Medicine, vol. 20, pp. 272-282, 2014.

[126] K.-S. R. S. Tudor, K. J. Payne, Y. Yamashita, and P. W. Kincade, "Functional assessment of precursors from murine bone marrow suggests a sequence of early B lineage differentiation events," Immunity, vol. 12, no. 3, pp. 335-345, 2000.

[127] M. K. Mann, A. Ray, S. Basu, C. L. Karp, and B. N. Dittel, "Pathogenic and regulatory roles for B cells in experimental autoimmune encephalomyelitis," Autoimmunity, vol. 45, no. 5, pp. 388-399, 2012.

[128] A. van der Goes, M. Kortekaas, K. Hoekstra, C. D. Dijkstra, and S. Amor, "The role of anti-myelin (auto)-antibodies in the phagocytosis of myelin by macrophages," Journal of Neuroimmunology, vol. 101, no. 1, pp. 61-67, 1999.

[129] M. C. Sadaba, J. Tzartos, C. Paino et al., "Axonal and oligodendrocyte-localized IgM and IgG deposits in MS lesions," Journal of Neuroimmunology, vol. 247, no. 1-2, pp. 86-94, 2012.

[130] R. P. Lisak, J. A. Benjamins, L. Nedelkoska et al., "Secretory products of multiple sclerosis B cells are cytotoxic to oligodendroglia in vitro," Journal of Neuroimmunology, vol. 246, no. 1-2, pp. 85-95, 2012.

[131] D. P. Harris, L. Haynes, and P. C. Sayles, "Reciprocal regulation of polarized cytokine production by effector B and T cells," Nature Immunology, vol. 1, no. 6, pp. 475-482, 2000.

[132] D. P. Harris, S. Goodrich, K. Mohrs, M. Mohrs, and F. E. Lund, "Cutting edge: the development of IL-4-producing B cells (B effector 2 cells) is controlled by IL- 4 , IL- 4 receptor $\alpha$, and Th2 cells," Journal of Immunology, vol. 175, no. 11, pp. 7103-7107, 2005.

[133] S. D. Wolf, B. N. Dittel, F. Hardardottir, and C. A. Janeway Jr., "Experimental autoimmune encephalomyelitis induction in genetically B cell-deficient mice," Journal of Experimental Medicine, vol. 184, no. 6, pp. 2271-2278, 1996.

[134] T. Matsushita, K. Yanaba, J.-D. Bouaziz, M. Fujimoto, and T. F. Tedder, "Regulatory B cells inhibit EAE initiation in mice while other B cells promote disease progression," Journal of Clinical Investigation, vol. 118, no. 10, pp. 3420-3430, 2008.

[135] S. Fillatreau, C. H. Sweenie, M. J. McGeachy, D. Gray, and S. M. Anderton, "B cells regulate autoimmunity by provision of IL10," Nature Immunology, vol. 3, no. 10, pp. 944-950, 2002.

[136] P. Shen, T. Roch, V. Lampropoulou et al., "IL-35-producing B cells are critical regulators of immunity during autoimmune and infectious diseases," Nature, vol. 507, no. 7492, pp. 366-370, 2014.

[137] J. B. Sun, C. F. Flach, C. Czerkinsky, and J. Holmgren, "B lymphocytes promote expansion of regulatory $\mathrm{T}$ cells in oral tolerance: powerful induction by antigen coupled to cholera toxin B subunit," Journal of Immunology, vol. 181, no. 12, pp. 8278-8287, 2008.

[138] M. S. Weber, T. Prod'homme, J. C. Patarroyo et al., "B-cell activation influences T-cell polarization and outcome of antiCD20 B-cell depletion in central nervous system autoimmunity," Annals of Neurology, vol. 68, no. 3, pp. 369-383, 2010.

[139] A. Ray, S. Basu, C. B. Williams, N. H. Salzman, and B. N. Dittel, "A novel IL-10-independent regulatory role for B cells in suppressing autoimmunity by maintenance of regulatory $\mathrm{T}$ cells via GITR ligand," Journal of Immunology, vol. 188, no. 7, pp. 3188-3198, 2012.

[140] N. L. Monson, P. Cravens, R. Hussain et al., "Rituximab therapy reduces organ-specific $\mathrm{T}$ cell responses and ameliorates 
experimental autoimmune encephalomyelitis," PLoS ONE, vol. 6, no. 2, Article ID e17103, 2011.

[141] T. A. Barr, P. Shen, S. Brown et al., "B cell depletion therapy ameliorates autoimmune disease through ablation of IL-6producing B cells," Journal of Experimental Medicine, vol. 209, no. 5, pp. 1001-1010, 2012.

[142] L. Moretta, G. Pietra, E. Montaldo et al., "Human NK cells: from surface receptors to the therapy of leukemias and solid tumors," Frontiers in Immunology, vol. 5, article 087, 2014.

[143] R. S. Goldszmid, A. Bafica, D. Jankovic et al., "TAP-1 indirectly regulates $\mathrm{CD} 4+\mathrm{T}$ cell priming in Toxoplasma gondii infection by controlling NK cell IFN- $\gamma$ production," Journal of Experimental Medicine, vol. 204, no. 11, pp. 2591-2602, 2007.

[144] Y. Matsumoto, K. Kohyama, Y. Aikawa et al., "Role of natural killer cells and TCR gamma delta T cells in acute autoimmune encephalomyelitis," European Journal of Immunology, vol. 28, no. 5, pp. 1681-1688, 1998.

[145] J. Hao, D. Campagnolo, R. Liu et al., "Interleukin-2/interleukin2 antibody therapy induces target organ natural killer cells that inhibit central nervous system inflammation," Annals of Neurology, vol. 69, no. 4, pp. 721-734, 2011.

[146] B.-N. Zhang, T. Yamamura, T. Kondo, M. Fujiwara, and T. Tabira, "Regulation of experimental autoimmune encephalomyelitis by natural killer (NK) cells," Journal of Experimental Medicine, vol. 186, no. 10, pp. 1677-1687, 1997.

[147] W. Xu, G. Fazekas, H. Hara, and T. Tabira, "Mechanism of natural killer (NK) cell regulatory role in experimental autoimmune encephalomyelitis," Journal of Neuroimmunology, vol. 163, no. 1-2, pp. 24-30, 2005.

[148] D. Huang, F.-D. Shi, S. Jung et al., "The neuronal chemokine CX3CL1/fractalkine selectively recruits NK cells that modify experimental autoimmune encephalomyelitis within the central nervous system," The FASEB Journal, vol. 20, no. 7, pp. 896-905, 2006.

[149] R. Winkler-Pickett, H. A. Young, J. M. Cherry et al., "In vivo regulation of experimental autoimmune encephalomyelitis by NK cells: alteration of primary adaptive responses," Journal of Immunology, vol. 180, no. 7, pp. 4495-4506, 2008.

[150] W. P. Chong, M. T. Ling, Y. Liu et al., "Essential role of NK cells in IgG therapy for experimental autoimmune encephalomyelitis," PLoS ONE, vol. 8, no. 4, Article ID e60862, 2013.

[151] H. Hammarberg, O. Lidman, C. Lundberg et al., "Neuroprotection by encephalomyelitis: rescue of mechanically injured neurons and neurotrophin production by CNS-infiltrating T and natural killer cells," Journal of Neuroscience, vol. 20, no. 14, pp. 5283-5291, 2000.

[152] I. Hamann, J. Dörr, R. Glumm et al., "Characterization of natural killer cells in paired CSF and blood samples during neuroinflammation," Journal of Neuroimmunology, vol. 254, no. 1-2, pp. 165-169, 2013.

[153] L. F. Kastrukoff, N. G. Morgan, D. Zecchini et al., "A role for natural killer cells in the immunopathogenesis of multiple sclerosis," Journal of Neuroimmunology, vol. 86, no. 2, pp. 123133, 1998.

[154] A. Lunemann, B. Tackenberg, T. DeAngelis et al., "Impaired IFN-gamma production and proliferation of NK cells in multiple sclerosis," International Immunology, vol. 23, no. 2, pp. 139148, 2011.

[155] D. Plantone, A. Marti, G. Frisullo et al., "Circulating CD56dim NK cells expressing perforin are increased in progressive multiple sclerosis," Journal of Neuroimmunology, vol. 265, no. 1-2, pp. 124-127, 2013.
[156] J. E. Martínez-Rodríguez, M. López-Botet, E. Munteis et al., "Natural killer cell phenotype and clinical response to interferon-beta therapy in multiple sclerosis," Clinical Immunology, vol. 141, no. 3, pp. 348-356, 2011.

[157] L. Sanvito, A. Tomita, N. Chihara et al., "Increase of Ki-67+ natural killer cells in multiple sclerosis patients treated with interferon- $\beta$ and interferon- $\beta$ combined with low-dose oral steroids," Journal of Neuroimmunology, vol. 236, no. 1-2, pp. 111117, 2011.

[158] B. Bielekova, M. Catalfamo, S. Reichert-Scrivner et al., "Regulatory CD56bright natural killer cells mediate immunomodulatory effects of IL-2R $\alpha$-targeted therapy (daclizumab) in multiple sclerosis," Proceedings of the National Academy of Sciences of the United States of America, vol. 103, no. 15, pp. 5941-5946, 2006.

[159] B. Bielekova, T. Howard, A. N. Packer et al., "Effect of antiCD25 antibody daclizumab in the inhibition of inflammation and stabilization of disease progression in multiple sclerosis," Archives of Neurology, vol. 66, no. 4, pp. 483-489, 2009.

[160] C. Chanvillard, J. M. Millward, M. Lozano et al., "Mitoxantrone induces natural killer cell maturation in patients with secondary progressive multiple sclerosis," PLoS ONE, vol. 7, no. 6, Article ID e39625, 2012.

[161] C. Lucchinetti, W. Brück, J. Parisi, B. Scheithauer, M. Rodriguez, and H. Lassmann, "Heterogeneity of multiple sclerosis lesions: implications for the pathogenesis of demyelination," Annals of Neurology, vol. 47, no. 6, pp. 707-717, 2000.

[162] B. Ajami, J. L. Bennett, C. Krieger, K. M. McNagny, and F. M. V. Rossi, "Infiltrating monocytes trigger EAE progression, but do not contribute to the resident microglia pool," Nature Neuroscience, vol. 14, no. 9, pp. 1142-1150, 2011.

[163] E. D. Ponomarev, L. P. Shriver, K. Maresz, and B. N. Dittel, "Microglial cell activation and proliferation precedes the onset of CNS autoimmunity," Journal of Neuroscience Research, vol. 81, no. 3, pp. 374-389, 2005.

[164] A. London, M. Cohen, and M. Schwartz, "Microglia and monocyte-derived macrophages: functionally distinct populations that act in concert in CNS plasticity and repair," Frontiers in Cellular Neuroscience, vol. 7, article 34, 2013.

[165] M. Prinz, T. L. Tay, Y. Wolf, and S. Jung, "Microglia: unique and common features with other tissue macrophages," Acta Neuropathologica, vol. 128, no. 3, pp. 319-331, 2014.

[166] A. Romero-Sandoval, N. Chai, N. Nutile-McMenemy, and J. A. DeLeo, "A comparison of spinal Ibal and GFAP expression in rodent models of acute and chronic pain," Brain Research, vol. 1219, pp. 116-126, 2008.

[167] M. Leinders, L. Knaepen, M. De Kock, C. Sommer, E. Hermans, and R. Deumens, "Up-regulation of spinal microglial Iba-1 expression persists after resolution of neuropathic pain hypersensitivity," Neuroscience Letters, vol. 554, pp. 146-150, 2013.

[168] M. J. Carson, C. R. Reilly, J. G. Sutcliffe, and D. Lo, "Mature microglia resemble immature antigen-presenting cells," Glia, vol. 22, no. 1, pp. 72-85, 1998.

[169] A. L. Ford, A. L. Goodsall, W. F. Hickey, and J. D. Sedgwick, "Normal adult ramified microglia separated from other central nervous system macrophages by flow cytometric sortingphenotypic differences defined and direct ex vivo antigen presentation to myelin basic protein-reactive CD4+ T cells compared," Journal of Immunology, vol. 154, no. 9, pp. 43094321, 1995.

[170] M. Makiko, P. A. Pino, N. Saederup, I. F. Charo, R. M. Ransohoff, and A. E. Cardona, "The fractalkine receptor but not CCR2 is 
present on microglia from embryonic development throughout adulthood," The Journal of Immunology, vol. 188, no. 1, pp. 2936, 2012.

[171] R. Shechter, A. London, C. Varol et al., "Infiltrating bloodderived macrophages are vital cells playing an anti-inflammatory role in recovery from spinal cord injury in mice," PLoS Medicine, vol. 6, no. 7, Article ID e1000113, 2009.

[172] M. Bhasin, M. Wu, and S. E. Tsirka, "Modulation of microglial/macrophage activation by macrophage inhibitory factor (TKP) or tuftsin (TKPR) attenuates the disease course of experimental autoimmune encephalomyelitis," $B M C$ Immunology, vol. 8, article 10, 2007.

[173] W. F. Wu, X. J. Tan, Y. B. Dai, V. Krishnan, M. Warner, and J. A. Gustafsson, "Targeting estrogen receptor beta in microglia and T cells to treat experimental autoimmune encephalomyelitis," Proceedings of the National Academy of Sciences of the United States of America, vol. 110, no. 9, pp. 3543-3548, 2013.

[174] E. D. Ponomarev, T. Veremeyko, N. Barteneva, A. M. Krichevsky, and H. L. Weiner, "MicroRNA-124 promotes microglia quiescence and suppresses EAE by deactivating macrophages via the C/EBP- $\alpha$-PU.1 pathway," Nature Medicine, vol. 17, no. 1, pp. 64-70, 2011.

[175] A. Aguzzi, B. A. Barres, and M. L. Bennett, "Microglia: scapegoat, saboteur, or something else?” Science, vol. 339, no. 6116, pp. 156-161, 2013.

[176] A. Chawla, K. D. Nguyen, and Y. P. S. Goh, "Macrophagemediated inflammation in metabolic disease," Nature Reviews Immunology, vol. 11, no. 11, pp. 738-749, 2011.

[177] P. J. Murray and T. A. Wynn, "Obstacles and opportunities for understanding macrophage polarization," Journal of Leukocyte Biology, vol. 89, no. 4, pp. 557-563, 2011.

[178] A. H. Ding, C. F. Nathan, and D. J. Stuehr, "Release of reactive nitrogen intermediates and reactive oxygen intermediates from mouse peritoneal macrophages: comparison of activating cytokines and evidence for independent production," Journal of Immunology, vol. 141, no. 7, pp. 2407-2412, 1988.

[179] A. Sica, T. Schioppa, A. Mantovani, and P. Allavena, "Tumourassociated macrophages are a distinct M2 polarised population promoting tumour progression: potential targets of anti-cancer therapy," European Journal of Cancer, vol. 42, no. 6, pp. 717-727, 2006.

[180] C. Liu, Y. Li, J. Yu et al., "Targeting the shift from M1 to M2 macrophages in experimental autoimmune encephalomyelitis mice treated with fasudil," PLoS ONE, vol. 8, no. 2, Article ID e54841, 2013.

[181] F. Porcheray, S. Viaud, A. C. Rimaniol et al., "Macrophage activation switching: an asset for the resolution of inflammation," Clinical and Experimental Immunology, vol. 142, no. 3, pp. 481489, 2005.

[182] J. Mikita, N. Dubourdieu-Cassagno, M. S. Deloire et al., "Altered M1/M2 activation patterns of monocytes in severe relapsing experimental rat model of multiple sclerosis. Amelioration of clinical status by M2 activated monocyte administration," Multiple Sclerosis, vol. 17, no. 1, pp. 2-15, 2011.

[183] M. Moreno, P. Bannerman, J. Ma et al., "Conditional ablation of astroglial CCL2 suppresses CNS accumulation of M1 macrophages and preserves axons in mice with MOG peptide EAE," The Journal of Neuroscience, vol. 34, no. 24, pp. 8175-8185, 2014.

[184] I. Vaknin, G. Kunis, O. Miller et al., "Excess circulating alternatively activated myeloid (M2) cells accelerate ALS progression while inhibiting experimental autoimmune encephalomyelitis," PLoS ONE, vol. 6, no. 11, Article ID e26921, 2011.

[185] Z. Kang, C. Z. Altuntas, M. F. Gulen et al., "Astrocyte-restricted ablation of interleukin-17-induced Actl-mediated signaling ameliorates autoimmune encephalomyelitis," Immunity, vol. 32, no. 3, pp. 414-425, 2010.

[186] R. R. Voskuhl, R. S. Peterson, B. Song et al., "Reactive astrocytes form scar-like perivascular barriers to leukocytes during adaptive immune inflammation of the CNS," Journal of Neuroscience, vol. 29, no. 37, pp. 11511-11522, 2009.

[187] R. Brambilla, T. Persaud, X. Hu et al., "Transgenic inhibition of astroglial NF- $\kappa \mathrm{B}$ improves functional outcome in experimental autoimmune encephalomyelitis by suppressing chronic central nervous system inflammation," Journal of Immunology, vol. 182, no. 5, pp. 2628-2640, 2009.

[188] R. Brambilla, P. D. Morton, J. J. Ashbaugh, S. Karmally, K. L. Lambertsen, and J. R. Bethea, "Astrocytes play a key role in EAE pathophysiology by orchestrating in the CNS the inflammatory response of resident and peripheral immune cells and by suppressing remyelination," GLIA, vol. 62 , no. 3, pp. 452-467, 2014.

[189] D. Wang, M. M. Ayers, D. V. Catmull, L. J. Hazelwood, C. C. A. Bernard, and J. M. Orian, "Astrocyte-associated axonal damage in pre-onset stages of experimental autoimmune encephalomyelitis," Glia, vol. 51, no. 3, pp. 235-240, 2005.

[190] M. Kipp, S. Gingele, F. Pott et al., "BLBP-expression in astrocytes during experimental demyelination and in human multiple sclerosis lesions," Brain, Behavior, and Immunity, vol. 25, no. 8, pp. 1554-1568, 2011.

[191] X. Wang, F. Haroon, S. Karray, and D. Schlüter, "Astrocytic Fas ligand expression is required to induce T-cell apoptosis and recovery from experimental autoimmune encephalomyelitis," European Journal of Immunology, vol. 43, no. 1, pp. 115-124, 2013.

[192] P. K. Mishra, H. Hsuchou, S. Ouyang, A. J. Kastin, X. Wu, and W. Pan, "Loss of astrocytic leptin signaling worsens experimental autoimmune encephalomyelitis," Brain, Behavior, and Immunity, vol. 34, pp. 98-107, 2013.

[193] H. Toft-Hansen, L. Füchtbauer, and T. Owens, "Inhibition of reactive astrocytosis in established experimental autoimmune encephalomyelitis favors infiltration by myeloid cells over $\mathrm{T}$ cells and enhances severity of disease," GLIA, vol. 59, no. 1, pp. 166-176, 2011.

[194] C. Hindinger, C. C. Bergmann, D. R. Hinton et al., "IFN- $\gamma$ signaling to astrocytes protects from autoimmune mediated neurological disability," PLoS ONE, vol. 7, no. 7, Article ID e42088, 2012.

[195] J. E. Merrill, L. J. Ignarro, M. P. Sherman, J. Melinek, and T. E. Lane, "Microglial cell cytotoxicity of oligodendrocytes is mediated through nitric oxide," Journal of Immunology, vol. 151, no. 4, pp. 2132-2141, 1993.

[196] K. J. Smith and H. Lassmann, "The role of nitric oxide in multiple sclerosis," The Lancet Neurology, vol. 1, no. 4, pp. 232241, 2002.

[197] O. Bagasra, F. H. Michaels, Y. M. Zheng et al., "Activation of the inducible form of nitric oxide synthase in the brains of patients with multiple sclerosis," Proceedings of the National Academy of Sciences of the United States of America, vol. 92, no. 26, pp. 1204112045, 1995.

[198] J. Witherick, A. Wilkins, N. Scolding, and K. Kemp, "Mechanisms of oxidative damage in multiple sclerosis and a cell therapy approach to treatment," Autoimmune Diseases, vol. 2011, Article ID 164608, 11 pages, 2011. 
[199] Y. Lin, G. Huang, S. Jamison et al., "PERK activation preserves the viability and function of remyelinating oligodendrocytes in immune-mediated demyelinating diseases," American Journal of Pathology, vol. 184, no. 2, pp. 507-519, 2014.

[200] Y. Hussien, D. R. Cavener, and B. Popko, "Genetic inactivation of PERK signaling in mouse oligodendrocytes: normal developmental myelination with increased susceptibility to inflammatory demyelination," GLIA, vol. 62, no. 5, pp. 680-691, 2014.

[201] Z. Ren, Y. Wang, D. Tao et al., "Overexpression of the dominant-negative form of interferon regulatory factor 1 in oligodendrocytes protects against experimental autoimmune encephalomyelitis," Journal of Neuroscience, vol. 31, no. 23, pp. 8329-8341, 2011.

[202] P. Patrikios, C. Stadelmann, A. Kutzelnigg et al., "Remyelination is extensive in a subset of multiple sclerosis patients," Brain, vol. 129, part 12, pp. 3165-3172, 2006.

[203] R. B. Tripathi, L. E. Rivers, K. M. Young, F. Jamen, and W. D. Richardson, "NG2 glia generate new oligodendrocytes but few astrocytes in a murine experimental autoimmune encephalomyelitis model of demyelinating disease," Journal of Neuroscience, vol. 30, no. 48, pp. 16383-16390, 2010.

[204] E. G. Rodriguez, C. Wegner, M. Kreutzfeldt et al., "Oligodendroglia in cortical multiple sclerosis lesions decrease with disease progression, but regenerate after repeated experimental demyelination," Acta Neuropathologica, vol. 128, no. 2, pp. 231246, 2014.

[205] R. Höftberger, S. Fink, F. Aboul-Enein et al., "Tubulin polymerization promoting protein (TPPP/p25) as a marker for oligodendroglial changes in multiple sclerosis," GLIA, vol. 58, no. 15, pp. 1847-1857, 2010.

[206] H. Kim, P. Walczak, C. Kerr et al., "Immunomodulation by transplanted human embryonic stem cell-derived oligodendroglial progenitors in experimental autoimmune encephalomyelitis," Stem Cells, vol. 30, no. 12, pp. 2820-2829, 2012.

[207] F. Sher, S. Amor, W. Gerritsen et al., "Intraventricularly injected Olig2-NSCs attenuate established relapsing-remitting EAE in mice," Cell Transplantation, vol. 21, no. 9, pp. 1883-1897, 2012.

[208] F. Girolamo, G. Ferrara, M. Strippoli et al., "Cerebral cortex demyelination and oligodendrocyte precursor response to experimental autoimmune encephalomyelitis," Neurobiology of Disease, vol. 43, no. 3, pp. 678-689, 2011.

[209] Q.-L. Cui, T. Kuhlmann, V. E. Miron et al., "Oligodendrocyte progenitor cell susceptibility to injury in multiple sclerosis," The American Journal of Pathology, vol. 183, no. 2, pp. 516-525, 2013.

[210] Z. Kang, C. Wang, J. Zepp et al., "Actl mediates IL-17-induced EAE pathogenesis selectively in NG2+ glial cells," Nature Neuroscience, vol. 16, no. 10, pp. 1401-1408, 2013. 


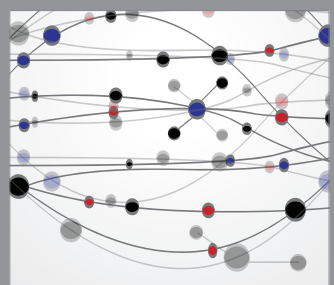

The Scientific World Journal
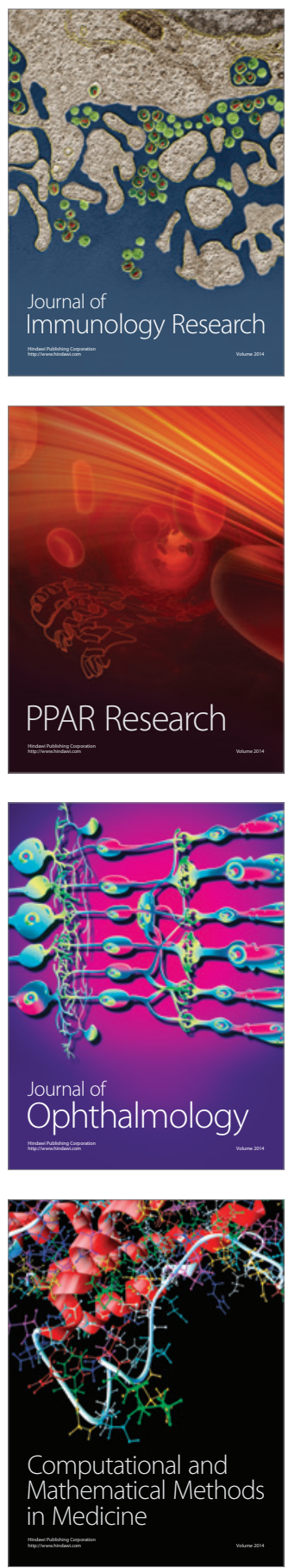

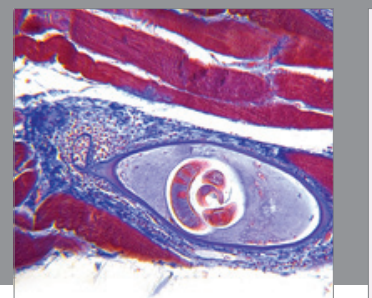

Gastroenterology

Research and Practice
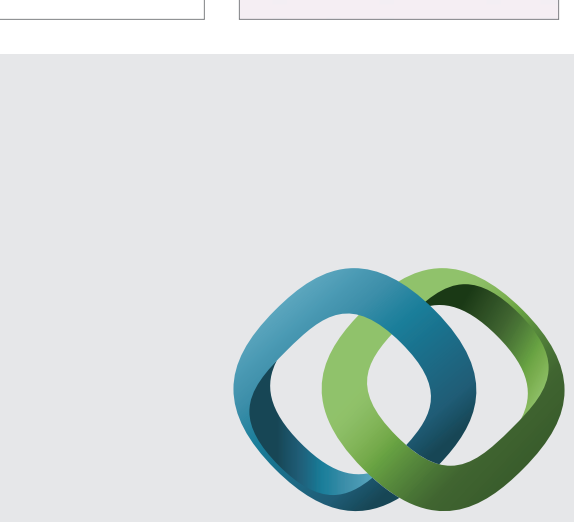

\section{Hindawi}

Submit your manuscripts at

http://www.hindawi.com
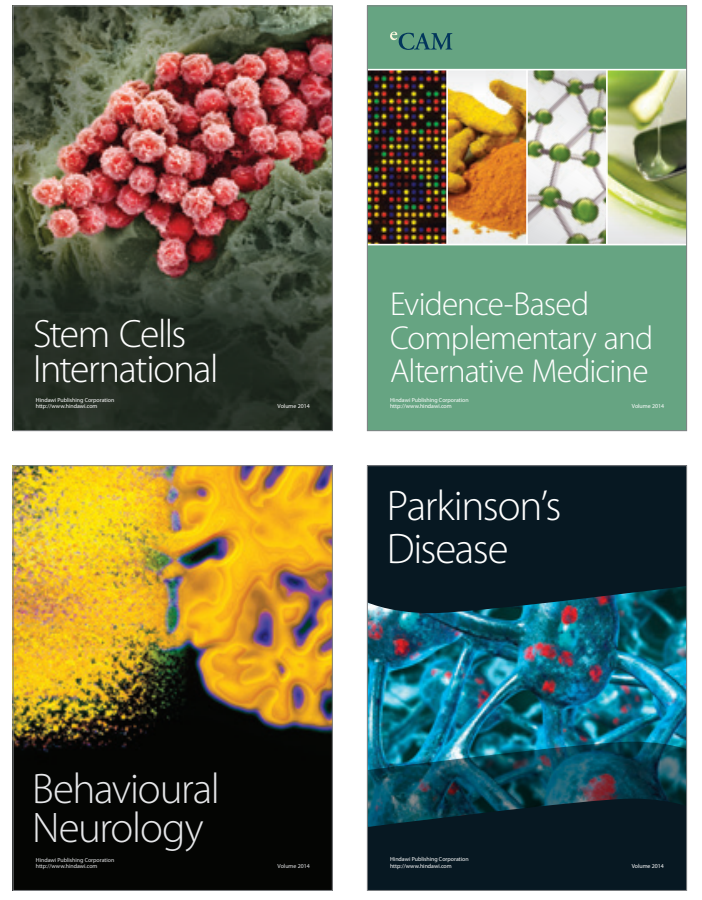
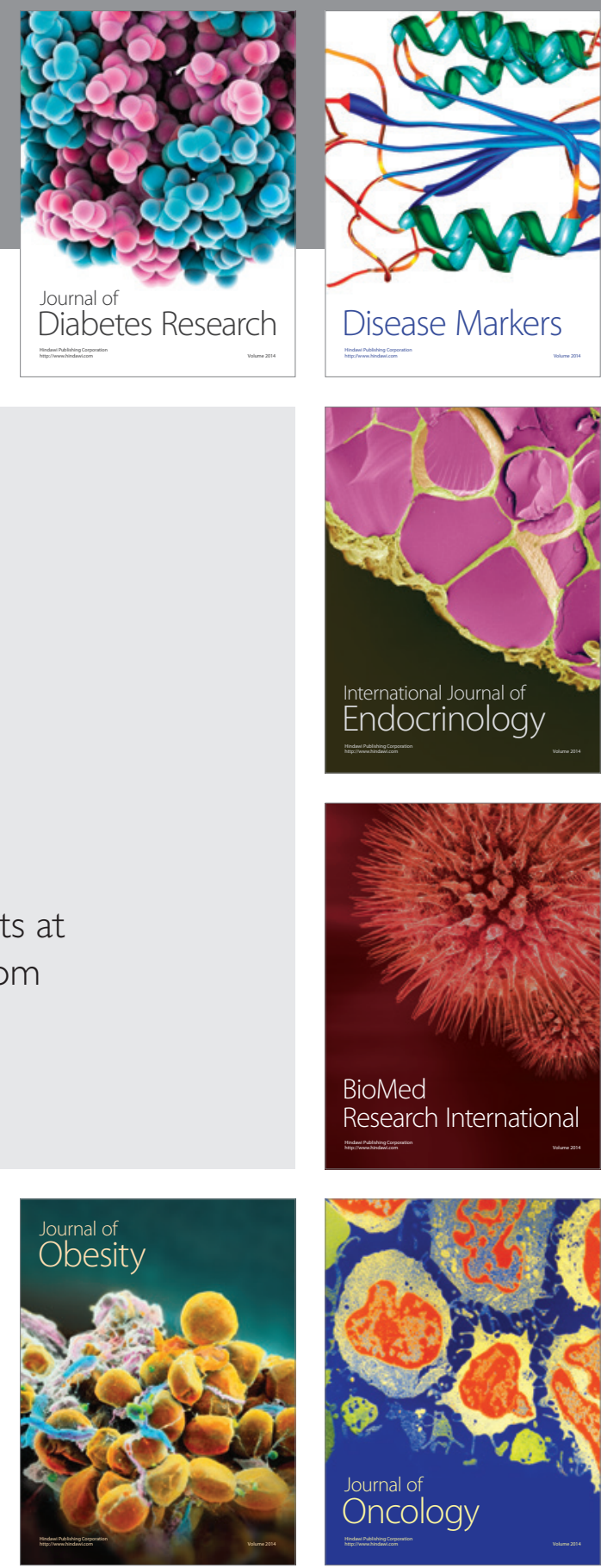

Disease Markers
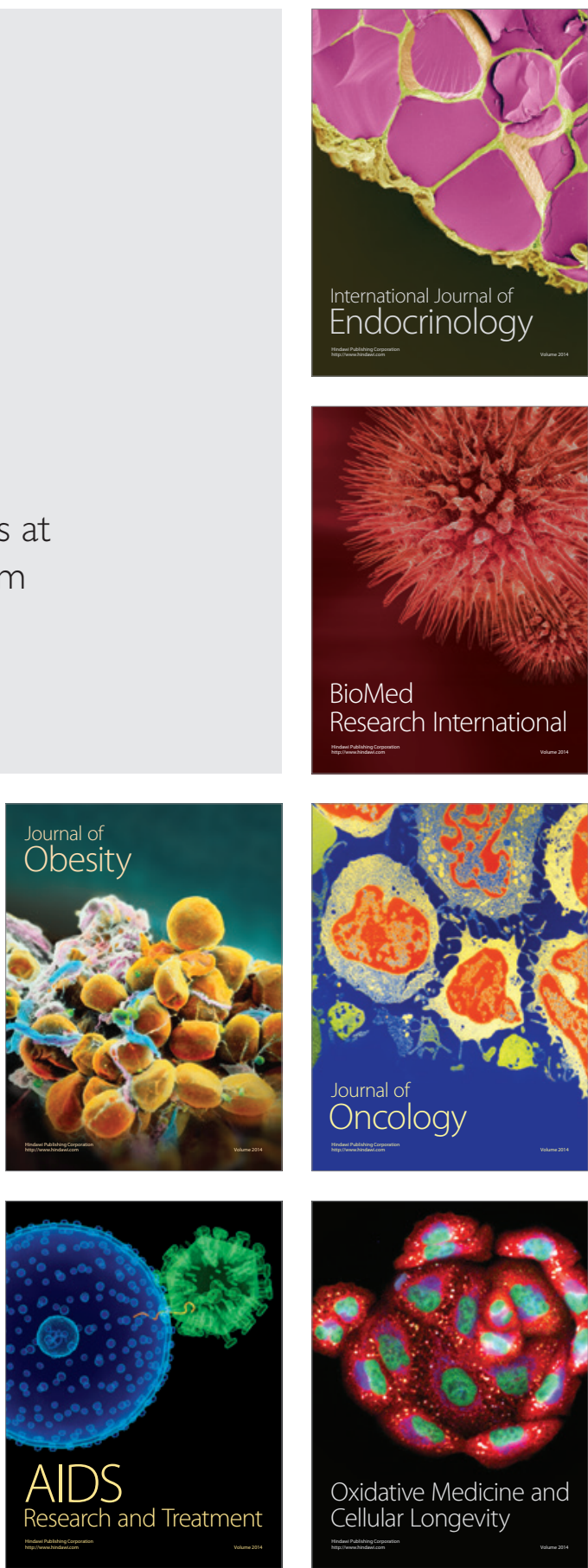